Review Article

\title{
BIOGENIC SYNTHESIS OF COPPER NANOPARTICLES AND THEIR BIOLOGICAL APPLICATIONS: AN OVERVIEW
}

\author{
SENTHIL KUMAR RAJU ${ }^{*}$ (i) , ANANDAKUMAR KARUNAKARAN² (iD), SHRIDHARSHINI KUMAR ${ }^{1}$ \\ SEKAR $^{1}$ (D) ${ }^{\text {MARUTHAMUTHU MURUGESAN }}{ }^{1}$ (iD) MOHANAPRIYA KARTHIKEYAN ${ }^{1}$ \\ PRAVEEN
}

1Department of Pharmaceutical Chemistry, Swamy Vivekanandha College of Pharmacy, Tiruchengode 637205, Tamilnadu, India, ${ }^{2}$ Department of Pharmaceutical Analysis, Swamy Vivekanandha College of Pharmacy, Tiruchengode 637205, Tamilnadu, India

Email: thrisen@gmail.com

Received: 10 Dec 2021, Revised and Accepted: 21 Jan 2022

\begin{abstract}
Copper nanoparticles are one of the most promising agents in the field of nanotechnology which has the widest range of applications in various fields. Copper is an inorganic and safest material to humans, extensively used as an anti-bacterial, anti-fungal, anti-cancer agent and also as catalysts and sensors in high potential, peculiarly in nanosize. This emerged the preparation of CuNPs using various techniques. Many conventional methods have been employed for the synthesizing CuNPs which include electron beam lithography, inert gas condensation, ion implantation, laser ablation, mechanical milling, mechanical grinding, pulsed wire discharge, spray pyrolysis, vacuum vapour deposition, chemical reduction method, electrochemical method, microemulsion method, microwave method and solvothermal decomposition method. Relatively the biological method is highly recommended for the synthesis of CuNPs due to the absence of harmless chemicals, enhanced biocompatibility, eco-friendly, greater biological activity and low toxicity. This review is focussing on the biogenic synthesis of CuNPs using plants and micro-organisms, reaction
\end{abstract} conditions, characterization techniques and their applications.

Keywords: Nanotechnology, Copper nanoparticles, Green synthesis, Plant extracts, Microorganisms, Biological applications

(C) 2022 The Authors. Published by Innovare Academic Sciences Pvt Ltd. This is an open access article under the CC BY license (https://creativecommons.org/licenses/by/4.0/) DOI: https://dx.doi.org/10.22159/ijpps.2022v14i3.43842. Journal homepage: https://innovareacademics.in/journals/index.php/ijpps.

\section{INTRODUCTION}

In modern material science and technology, one of the most active areas of research is nanotechnology. Nanotechnology is a transformation tool used to enhance the development of highly valuable products from renewable and biocompatible raw materials. Nanotechnology mainly aims in the study of particles ranging from 1-100 $\mathrm{nm}$ approximately and these particles are said to be Nanoparticles (NPs). Nanoparticles are useful for delivering medications to the target specific locations. Interaction of the nanoparticles with humans and the diversity of organisms in an environment is an essential thing to be considered [1-5]. Nanoparticles are found to exhibit enhanced optical and catalytic activity due to the quantum size effect. NPs have an enhanced effect on various properties due to their Surface Plasmon Resonance (SPR) enhanced Rayleigh scattering and surface-enhanced Raman scattering (SERS) which makes them more constant as compared to bulk metals. NPs have distinct chemical, physical, electrical, electronic, magnetic, mechanical, optical and biological properties. Metal nanoparticles are widely employed in various fields because of their unique characters including the large surface area to volume ratio, large surface energies, plasmon excitation, short-range ordering and quantum confinement. Among the transition metals, copper has a better view of both science and technology because it is a reusable metal [3].

Copper is one of the most extensively utilized materials on the planet and is found in both plant and animal tissues. It is a prominent metal of therapeutics which can be utilized for various pathological conditions like wound, bacterial and fungal infections. It would be an anti-fouling, anti-bacterial, anti-fungal agent etc. that can be used to purify the water. It also helped in crosslinking of collagen, formation of bone matrix and preventing the wound from infection. According to the U.S. EPA (United States Environmental Protection Agency), copper is the only solid surface material that destroys microorganisms. Due to the fascinating physical, optical and electronic properties, it is subjected to the intense research of nanoscience [7-9].

Copper nanoparticles (CuNPs) are more advantageous because they can be easily synthesised at a low cost, show an intense colour and exhibit a strong tunable absorption band in the visible region, which is not present in the bulk metals. CuNPs are highly toxic to microorganisms, exhibits a strong bactericidal effect on many species of bacteria, also act as antifungal, anti-inflammatory agents and works in preventing infecting and wound healing. The drawback of CuNPs is the severe susceptibility to oxidation that makes their catalytic and optical reactions non-reproducible [6-9]. But CuNPs can resist oxidation or aggregation, by stabilizing through the adsorption or by the covalent attachment of the organic compounds on the surface of the NPs which provides the electrostatic or electrostatic repulsive forces between particles. NPs can be synthesised in two ways: top-down and bottom-up approach (fig. 1).

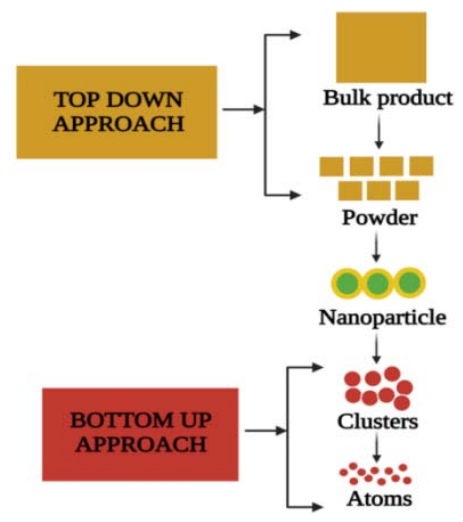

Fig. 1: Approaches for the synthesis of nanoparticles

The top-down approach is a process of breaking down the bulk material into nano-sized particles. The bottom-up approach is a process of building nanoparticles using atoms. There are three different processes to generate nanoparticles based on these two approaches viz., physical, chemical and biological methods. Among these three methods, the physical method is classified as a top-down approach, whereas the other two ways are classified as bottom-up approaches (fig. 2). 


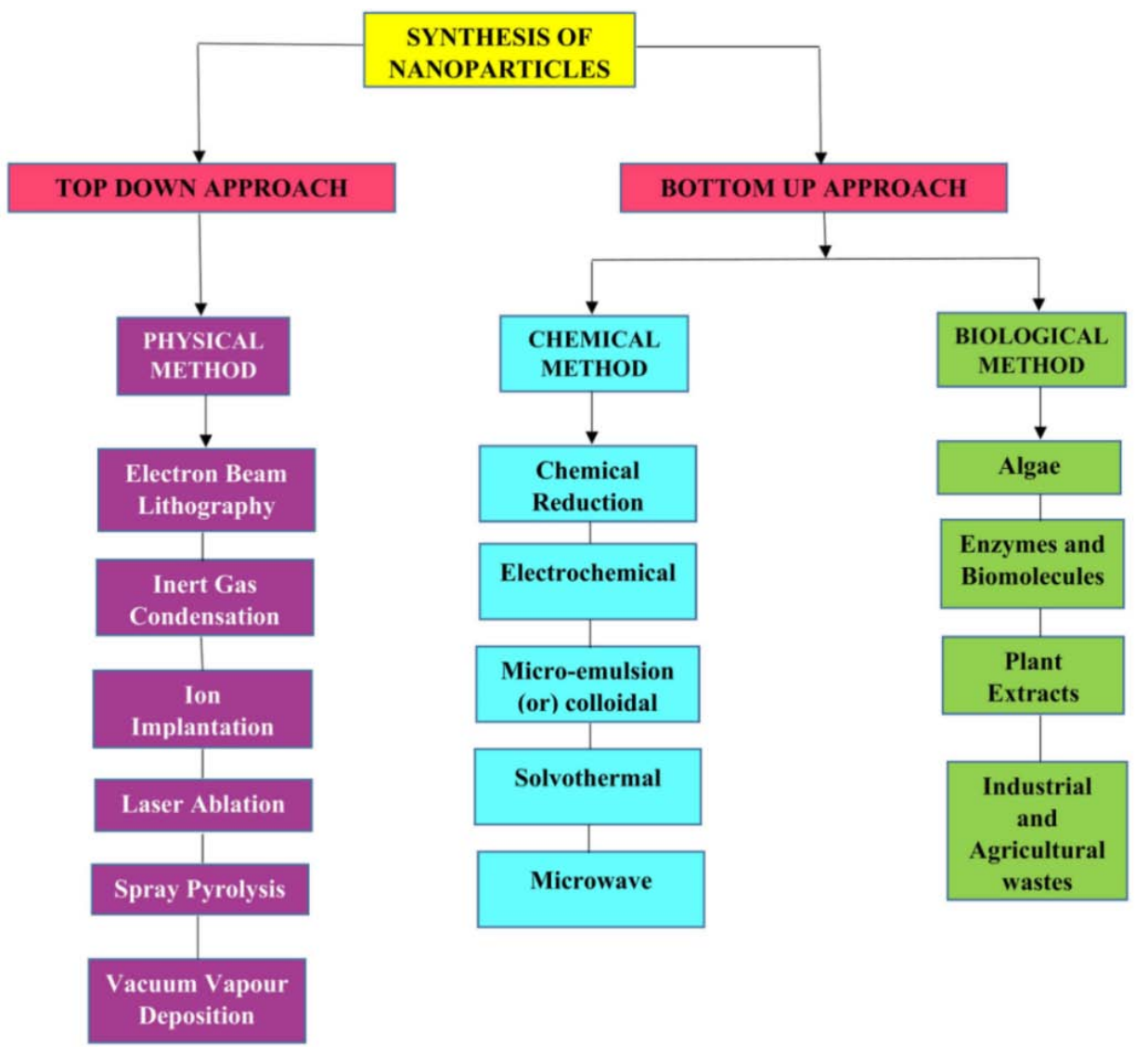

Fig. 2: Methods for the synthesis of nanoparticles

In comparison with the conventional physical and chemical methods, the biological method plays a greater role in the synthesis of NPs because it is a simple, eco-friendly, non-toxic and economical method [11] (fig. 3).

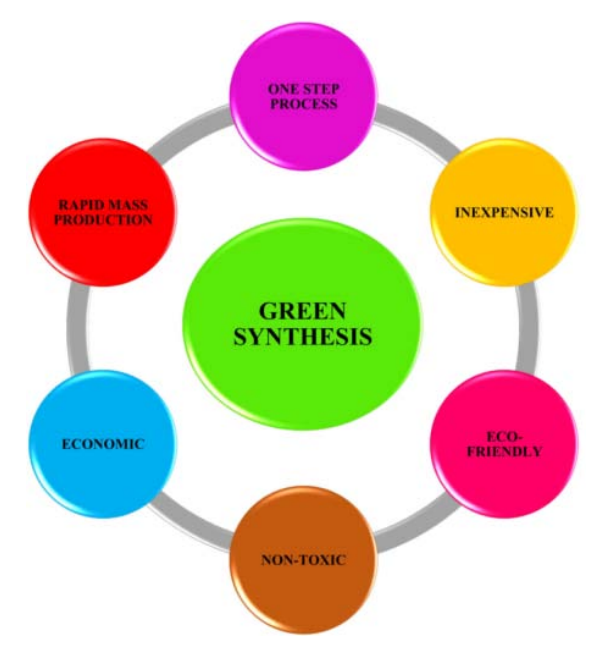

Fig. 3: Advantages of green synthesised CuNPs

In the biological method, either plants or microorganisms can be mediated for synthesizing CuNPs. The plant-mediated synthesis is an eco-friendly method which requires less drastic reaction conditions and inexpensive reagents. Three main steps involved in the green synthesis of CuNPs are choice of solvent used, choice of the ecofriendly reducing agent and the choice of a non-toxic material for the stabilization of the nanoparticles. Most of the synthetic methods have reported on organic solvents due to the hydrophobicity of the capping agents used. The synthesis of CuNPs using biological methods is more compatible with the green synthesis because the methods are eco-friendly; same components act as reducing and capping agents [12].

In this review, only the literature indexed in ScienceDirect, PubMed, Springer, Google Scholar, ResearchGate, Research square and Royal Society of Chemistry databases between the time period of 2015 and 2021 were surveyed. The keywords for this survey include copper nanoparticles, green synthesis, microwave irradiation, biological synthesis, characterization, applications of copper nanoparticles, both individually and in combination were applied and shortlisted according to the purpose of this study. This review focuses on various plant extracts and micro-organisms employed for the biological synthesis of the CuNPs along with their reaction conditions, characterization techniques and their various biological applications (fig. 4).

\section{Mechanism of synthesis of nanoparticles}

In the biosynthesis of CuNPs, extracts from biological sources may act as both reducing and capping agents. Combinations of biomolecules included in these extracts, such as proteins, amino acids, vitamins, and polysaccharides, reduce $\mathrm{Cu}^{+}$ions in an environmentally favourable but chemically complex. Copper ions were bound on the surface of proteins in extract via electrostatic interactions, which served as a reduction process [11, 19]. (fig. 5).

\section{Plant mediated synthesis of copper nanoparticles}

The main advantage of the green synthesis of CuNPs is that they are easily available, safe to handle and possess a broad variability of metabolites. In the light of IR spectroscopic research, the primary phytochemicals responsible have been identified as terpenoids, flavones, ketones, aldehydes, amides, and carboxylic acids. The main 
water-soluble phytochemicals like quinones, flavones and organic acids were responsible for immediate reduction. Redial tautomerization occurs in anthraquinone compounds, resulting in the formation of nanoparticles. The stability of the green synthesized CuNPs is enhanced and thereby it increases the rate of reaction of
CuNPs by preventing the formation of agglomerates [13, 17]. The part of the plants such as leaf, fruit, flower, bark, root and stem along with the precursor copper salts such as copper acetate, copper nitrate, copper sulphate and copper chloride were processed as per the time and temperature is given in table 1 and fig. 6 .

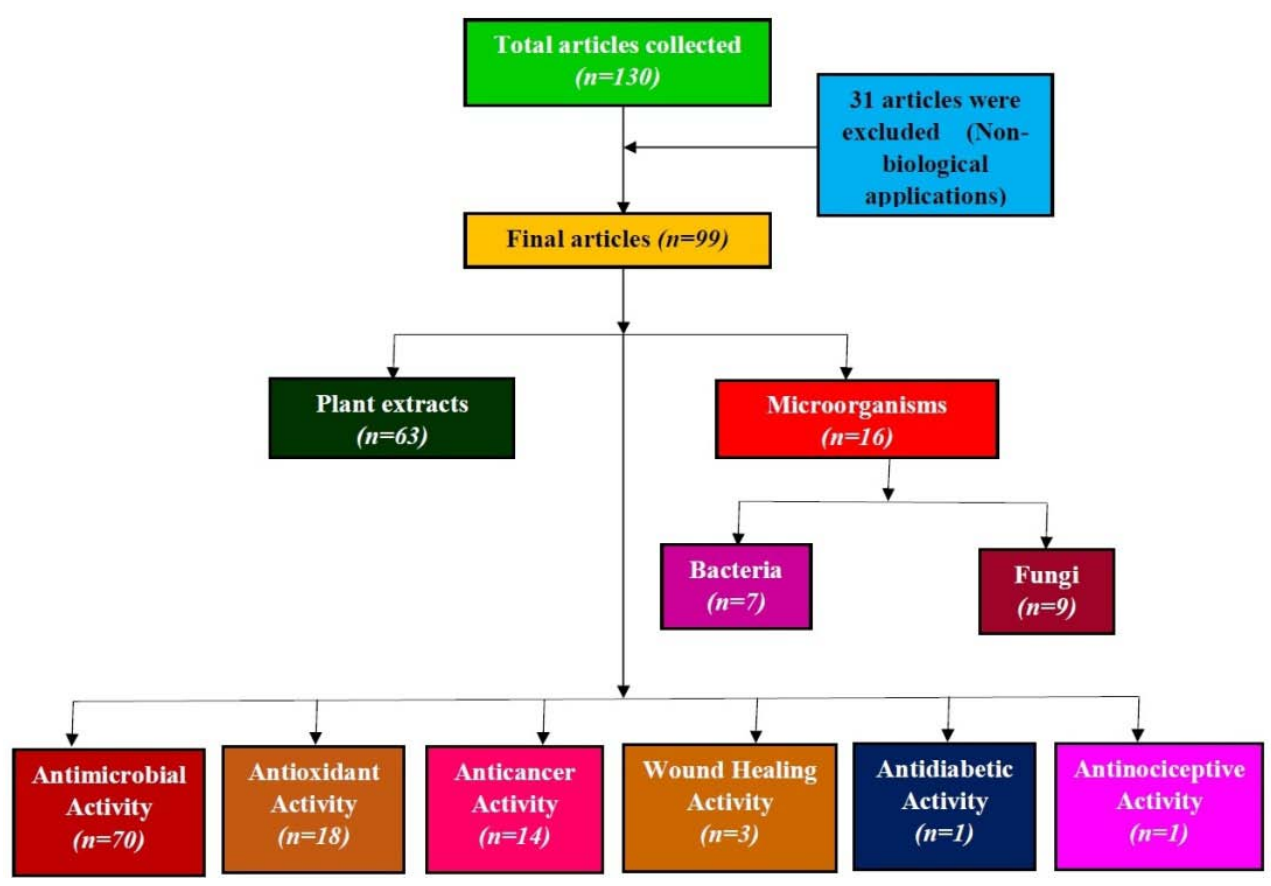

Fig. 4: Selection strategy of this review

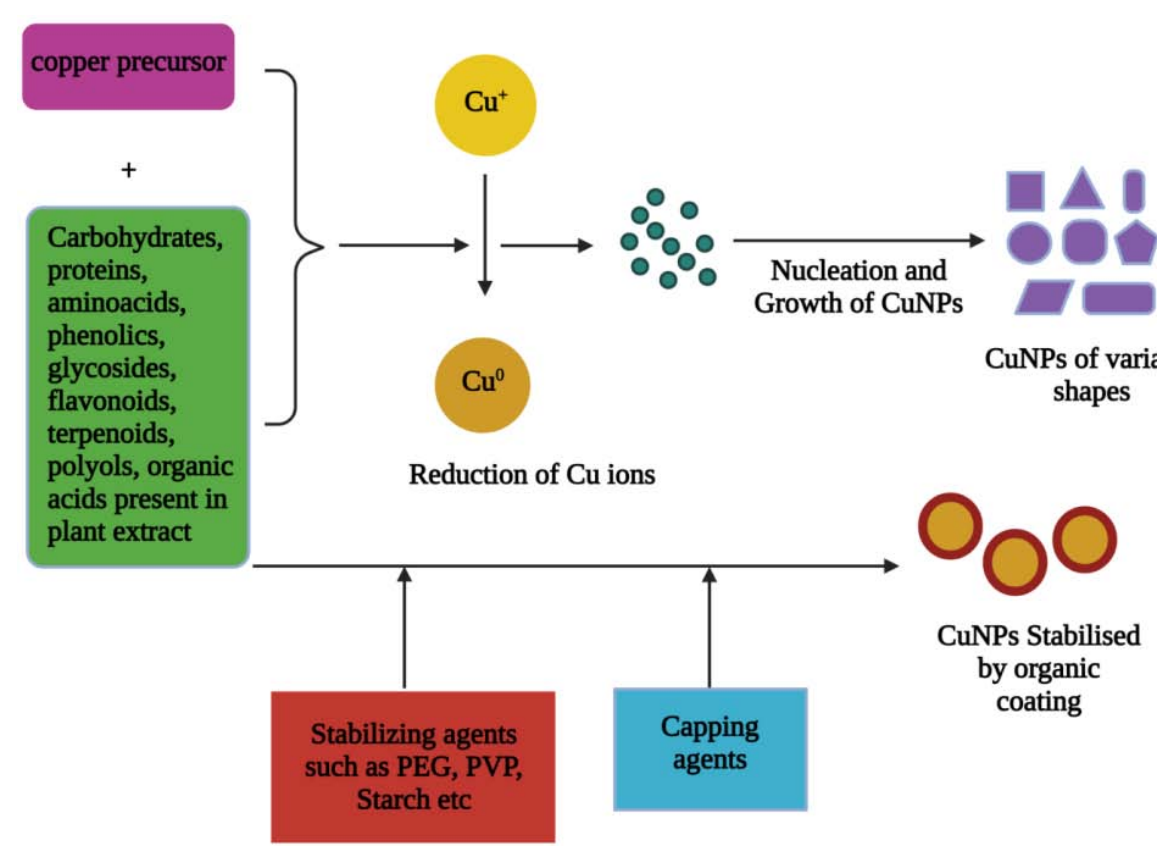

Fig. 5: Probable mechanism for the synthesis of CuNPs

\section{Microorganisms mediated synthesis of copper nanoparticles}

For the biological synthesis of CuNPs, various green algae, bacteria, viruses and fungi were used. Microorganisms are a good source for the production of CuNPs because of their metabolism and ease of growth in laboratory conditions. Initially, bacteria were used to synthesize NPs and this was later succeeded with the use of fungi because they are easier to handle on comparing with the other group of microorganisms [5]. Microbiological methods synthesize nanoparticles at a slower rate of reaction than that observed when plant extracts are used. CuNPs were prepared from various bacteria and fungi along with the precursor copper salts are given in table 2 and table 3 , respectively. The probable mechanism of the formation of copper nanoparticles is shown in fig. 7. 
Table 1: Plant mediated synthesis of copper nanoparticles

\begin{tabular}{|c|c|c|c|c|c|c|}
\hline Plant name & Parts used & Phyto constituents & Precursor & Temp $\left({ }^{\circ} \mathrm{C}\right) /$ time & Activity & References \\
\hline Allium sativum & Leaves & Steroid saponins & $\begin{array}{l}1 \text { mmol Copper } \\
\text { sulphate }\end{array}$ & $\mathrm{RT}, 48 \mathrm{~h}$ & Antibacterial & {$[1]$} \\
\hline Allium sativum & Herb & $\begin{array}{l}\text { Sulphides, } \\
\text { thiosulfinates, vinyldithiins }\end{array}$ & $\begin{array}{l}2 \text { mmol Copper } \\
\text { chloride }\end{array}$ & RT, Nil & $\begin{array}{l}\text { Antibacterial, } \\
\text { anticancer }\end{array}$ & {$[4]$} \\
\hline Zingiber officinale & Rhizome & Phenols and terpenes & $\begin{array}{l}2 \text { mmol Copper } \\
\text { chloride }\end{array}$ & RT, Nil & $\begin{array}{l}\text { Antibacterial, } \\
\text { anticancer }\end{array}$ & {$[4]$} \\
\hline Cissus quadrangularis & Leaves & $\begin{array}{l}\text { Quercitin, quercitrin, } \\
\text { beta-sitosterol }\end{array}$ & $\begin{array}{l}1 \text { mmol Copper } \\
\text { acetate }\end{array}$ & 300-400, Nil & Antifungal & {$[10]$} \\
\hline Moringa oleifera & Leaves & $\begin{array}{l}\text { Flavonoids, alkaloids, } \\
\text { phenols, vitamins, minerals }\end{array}$ & $\begin{array}{l}0.04 \mathrm{M} \mathrm{Cu}+2 \\
\text { solution }\end{array}$ & $60,3 \mathrm{~h}$ & $\begin{array}{l}\text { Antibacterial, } \\
\text { antifungal, } \\
\text { antioxidant }\end{array}$ & [13] \\
\hline Azadirachta indica & Leaves & $\begin{array}{l}\text { Azadirachtin, nimbin, } \\
\text { nimbidin, quercetin }\end{array}$ & $\begin{array}{l}0.2 \mathrm{M} \text { Copper } \\
\text { acetate }\end{array}$ & $120,2 \mathrm{~h}$ & $\begin{array}{l}\text { Anticancer, } \\
\text { antioxidant }\end{array}$ & {$[14]$} \\
\hline Hibiscus rosa-sinensis & Leaves & $\begin{array}{l}\text { Tannins, anthraquinones, } \\
\text { quinines, phenols, } \\
\text { flavonoids, alkaloids }\end{array}$ & $\begin{array}{l}0.2 \mathrm{M} \text { Copper } \\
\text { acetate }\end{array}$ & $120,2 \mathrm{~h}$ & $\begin{array}{l}\text { Anticancer, } \\
\text { antioxidant }\end{array}$ & {$[14]$} \\
\hline Murraya koenigii & Leaves & Polyphenols & $\begin{array}{l}0.2 \mathrm{M} \text { Copper } \\
\text { acetate }\end{array}$ & $120,2 \mathrm{~h}$ & $\begin{array}{l}\text { Anticancer, } \\
\text { antioxidant }\end{array}$ & {$[14]$} \\
\hline Tamarindus indica & Leaves & $\begin{array}{l}\text { Tannins, alkaloid, } \\
\text { flavonoids, sesquiterpenes, } \\
\text { glycosides }\end{array}$ & $\begin{array}{l}0.2 \mathrm{M} \text { Copper } \\
\text { acetate }\end{array}$ & $120,2 \mathrm{~h}$ & $\begin{array}{l}\text { Anticancer, } \\
\text { antioxidant }\end{array}$ & {$[14]$} \\
\hline Eclipta prostrata & Leaves & $\begin{array}{l}\text { P-caryophyllene, } \alpha \text { - } \\
\text { humulene }\end{array}$ & $\begin{array}{l}3 \text { mmol Copper } \\
\text { acetate }\end{array}$ & RT, $24 \mathrm{~h}$ & $\begin{array}{l}\text { Anticancer, } \\
\text { antioxidant }\end{array}$ & {$[15]$} \\
\hline Abutilon Indicum & Leaves & $\begin{array}{l}\text { Carbohydrates, steroids, } \\
\text { glycosides, flavonoids, } \\
\text { tannins, phenolic } \\
\text { compound }\end{array}$ & Copper nitrate & $200,2 \mathrm{~h}$ & $\begin{array}{l}\text { Antibacterial, } \\
\text { antifungal, } \\
\text { anticancer, } \\
\text { antioxidant }\end{array}$ & {$[16]$} \\
\hline Clerodendrum inerme & Leaves & Beta sitosterol & Copper nitrate & $200,2 \mathrm{~h}$ & $\begin{array}{l}\text { Antibacterial, } \\
\text { antifungal, } \\
\text { anticancer, } \\
\text { antioxidant }\end{array}$ & {$[16]$} \\
\hline $\begin{array}{l}\text { Clerodendrum } \\
\text { infortunatum }\end{array}$ & Leaves & Saponin & Copper nitrate & $200,2 \mathrm{~h}$ & $\begin{array}{l}\text { Antibacterial, } \\
\text { antifungal, } \\
\text { anticancer, } \\
\text { antioxidant }\end{array}$ & [16] \\
\hline Eryngium caucasicum & Leaves & $\begin{array}{l}\text { Octane, carvone, beta } \\
\text { ionene, beta bisaboline }\end{array}$ & $\begin{array}{l}10 \text { mmol cupric } \\
\text { nitrate }\end{array}$ & $\mathrm{RT}, 72 \mathrm{~h}$ & $\begin{array}{l}\text { Antibacterial, } \\
\text { antioxidant }\end{array}$ & [17] \\
\hline Curcuma longa & Rhizome & Curcumin, deoxy curcumin & Copper sulphate & $\mathrm{RT}, 30 \mathrm{~min}$ & Antifungal & [18] \\
\hline Vaccinium myrtillus & Fruit & Phenols & $\begin{array}{l}0.1 \text { M Copper } \\
\text { chloride, Copper } \\
\text { acetate, Copper } \\
\text { nitrate }\end{array}$ & RT, $14 \mathrm{~h}$ & $\begin{array}{l}\text { Antibacterial, } \\
\text { antifungal }\end{array}$ & [19] \\
\hline Vaccinium uliginosum & Fruit & Anthocyanin & $\begin{array}{l}0.1 \text { M Copper } \\
\text { chloride, Copper } \\
\text { acetate, Copper } \\
\text { nitrate }\end{array}$ & RT, $14 \mathrm{~h}$ & $\begin{array}{l}\text { Antibacterial, } \\
\text { antifungal }\end{array}$ & [19] \\
\hline Cucumis sativus & Root & Anthocyanin & CuNPs purchased & $25,12 \mathrm{~h}$ & $\begin{array}{l}\text { Anticancer, } \\
\text { antioxidant }\end{array}$ & {$[20]$} \\
\hline Anethum graveolens & Seeds & $\begin{array}{l}\text { Volatile oil, flavonoids, } \\
\text { coumarins, xanthones, } \\
\text { triterpenes }\end{array}$ & Copper chloride & $35,24 \mathrm{~h}$ & Antifungal & {$[21]$} \\
\hline Thymus daenensis & Leaves & $\begin{array}{l}\text { Thymol, carvacrol, linalool, } \\
\text { a-terpineol }\end{array}$ & Copper chloride & $35,24 \mathrm{~h}$ & Antifungal & {$[21]$} \\
\hline Persea Americana & Seeds & Flavonol glycoside & Copper sulphate & $45-50,6-7 \mathrm{~h}$ & $\begin{array}{l}\text { Antibacterial, } \\
\text { antifungal, } \\
\text { antioxidant }\end{array}$ & {$[22]$} \\
\hline $\begin{array}{l}\text { Trigonella foenum- } \\
\text { graecum }\end{array}$ & Seeds & $\begin{array}{l}\text { Carbohydrates, proteins, } \\
\text { lipids, alkaloids, flavonoids, } \\
\text { steroidal saponins }\end{array}$ & $\begin{array}{l}2.0 \text { mmol Copper } \\
\text { sulphate }\end{array}$ & $121,20 \mathrm{~min}$ & $\begin{array}{l}\text { Antibacterial, } \\
\text { antifungal, } \\
\text { antioxidant }\end{array}$ & {$[23]$} \\
\hline Punica granatum & Peel & $\begin{array}{l}\text { Flavonoids, ellagitannin, } \\
\text { punicalagin, ellagic acid }\end{array}$ & Copper sulphate & $40,48 \mathrm{~h}$ & Antibacterial & {$[24]$} \\
\hline Fagus sylvatica & Sapwood & $\begin{array}{l}\text { Epicatechin, catechin, } \\
\text { protocatechuic acid, } \\
\text { isoquercitrin }\end{array}$ & Copper sulphate & Vacuum $80 \mathrm{KPa}, 2 \mathrm{~h}$ & Antifungal & {$[25]$} \\
\hline Pinus sylvestris & Sapwood & $\begin{array}{l}\alpha \text {-terpineol, linalool, } \\
\text { limonene }\end{array}$ & Copper sulphate & Vacuum $80 \mathrm{KPa}, 2 \mathrm{~h}$ & Antifungal & {$[25]$} \\
\hline Cissus vitiginea & Leaves & $\begin{array}{l}\text { Tannin, phenol, flavonoid, } \\
\text { terpenoids, saponin }\end{array}$ & $\begin{array}{l}10 \text { mmol Copper } \\
\text { sulphate }\end{array}$ & RT, Nil & $\begin{array}{l}\text { Antibacterial, } \\
\text { antioxidant }\end{array}$ & [26] \\
\hline Citrus medica & $\begin{array}{l}\text { Juice of } \\
\text { matured } \\
\text { fruits }\end{array}$ & $\begin{array}{l}\text { Vitamin C, pectin, citral, } \\
\text { limonene, phenolics }\end{array}$ & $\begin{array}{l}100 \mathrm{mmol} \\
\text { Copper sulphate }\end{array}$ & 60-100, Nil & $\begin{array}{l}\text { Antibacterial, } \\
\text { antifungal }\end{array}$ & [27] \\
\hline
\end{tabular}




\begin{tabular}{|c|c|c|c|c|c|c|}
\hline Plant name & Parts used & Phyto constituents & Precursor & Temp $\left({ }^{\circ} \mathrm{C}\right) /$ time & Activity & References \\
\hline Azadirachta indica & Leaves & $\begin{array}{l}\text { Azadirachtin, nimbin, } \\
\text { nimbidin, gedunin, } \\
\text { salannin, quercetin }\end{array}$ & $\begin{array}{l}1 \text { mmol Copper } \\
\text { sulphate }\end{array}$ & $70-90,24 \mathrm{~h}$ & Antifungal & {$[29]$} \\
\hline Ocimum sanctum & Leaves & $\begin{array}{l}\text { Linalool, carvacrol, beta } \\
\text { caryophyllene, germacrene }\end{array}$ & $\begin{array}{l}1 \text { mmol Copper } \\
\text { sulphate }\end{array}$ & RT, Nil & $\begin{array}{l}\text { Antibacterial, } \\
\text { antifungal }\end{array}$ & {$[30]$} \\
\hline Allium saralicum & Leaves & $\begin{array}{l}\text { Neophytadiene, phytol, } \\
\text { vitamin E, tocopherol }\end{array}$ & Copper sulphate & $\mathrm{RT}, 1 \mathrm{~h}$ & $\begin{array}{l}\text { Antibacterial, } \\
\text { anticancer, } \\
\text { antifungal, } \\
\text { antioxidant, } \\
\text { wound healing }\end{array}$ & {$[31]$} \\
\hline Allium eriophyllum & Leaves & $\begin{array}{l}\text { Carvacrol, geranyl acetone, } \\
\text { beta ionone }\end{array}$ & $\begin{array}{l}0.04 \text { M Copper } \\
\text { sulphate }\end{array}$ & $60,15 \mathrm{~min}$ & $\begin{array}{l}\text { Antibacterial, } \\
\text { anticancer, } \\
\text { antifungal, } \\
\text { antioxidant, } \\
\text { wound healing }\end{array}$ & {$[32]$} \\
\hline Zingiber officinale & rhizome & Phenols, terpenes & Copper sulphate & $50,20 \mathrm{~min}$ & $\begin{array}{l}\text { Antibacterial, } \\
\text { antifungal, } \\
\text { antioxidant }\end{array}$ & [33] \\
\hline Celastrus paniculatus & Leaves & Alkaloids, sterols & $\begin{array}{l}5 \text { mmol Copper } \\
\text { sulphate }\end{array}$ & $60,20 \mathrm{~min}$ & Antifungal & {$[34]$} \\
\hline Triticum aestivum & Seeds & Protein, starch & Copper sulphate & $25,12 \mathrm{~h}$ & Antioxidant & [35] \\
\hline Tilia cordata & Leaves & Flavonoids & Copper sulphate & $100,12 \mathrm{~h}$ & $\begin{array}{l}\text { Antibacterial, } \\
\text { anticancer }\end{array}$ & [36] \\
\hline Syzygium aromaticum & Bud & $\begin{array}{l}\text { Terpenes, phenols, } \\
\text { hydrocarbons }\end{array}$ & Cupric acetate & $80,5 \mathrm{~min}$ & $\begin{array}{l}\text { Antibacterial, } \\
\text { antifungal }\end{array}$ & [37] \\
\hline Falcaria vulgaris & Leaves & Carvacrol, Spatulenul & $\begin{array}{l}0.04 \text { M Copper } \\
\text { sulphate }\end{array}$ & $40,30 \mathrm{~min}$ & $\begin{array}{l}\text { Antibacterial, } \\
\text { anticancer, } \\
\text { antifungal, } \\
\text { antioxidant, } \\
\text { wound healing }\end{array}$ & {$[38]$} \\
\hline Camellia sinensis & Leaves & Flavonoids, polyphenols & $\begin{array}{l}1 \text { mmol Copper } \\
\text { sulphate }\end{array}$ & $80,10 \mathrm{~min}$ & $\begin{array}{l}\text { Antibacterial, } \\
\text { antifungal }\end{array}$ & [39] \\
\hline Manilkara zapota & Leaves & $\begin{array}{l}\text { Vitamin C, niacin, } \\
\text { stearic acid, pantothenic } \\
\text { acid }\end{array}$ & $\begin{array}{l}5 \text { mmol Copper } \\
\text { sulphate }\end{array}$ & $100,10 \mathrm{~min}$ & $\begin{array}{l}\text { Antibacterial, } \\
\text { antifungal, } \\
\text { anticancer }\end{array}$ & {$[40]$} \\
\hline Citrus limon & Fruits & $\begin{array}{l}\text { Limonene, citronellol, } \\
\text { geranial }\end{array}$ & Copper sulphate & $27,4 \mathrm{~h}$ & Antibacterial & {$[41]$} \\
\hline Zizipus spina-christi & Fruit & $\begin{array}{l}\text { Alpha and beta pinene, } \\
\text { trans-caryophyllene }\end{array}$ & $\begin{array}{l}\text { 0.02M Copper } \\
\text { sulphate }\end{array}$ & $80,1 \mathrm{~h}$ & Antibacterial & {$[42]$} \\
\hline Piper retrofractum & Fruit & $\begin{array}{l}\text { Alkaloids, } \\
\text { phenylpropanoids, alkyl } \\
\text { glycoside, lignans }\end{array}$ & Copper sulphate & $60,1 \mathrm{~h}$ & Antibacterial & {$[43]$} \\
\hline Piper longum & Powder & $\begin{array}{l}\text { Sesquiterpene } \\
\text { hydrocarbons, ethers }\end{array}$ & Copper sulphate & $60,30 \mathrm{~min}$ & Antibacterial & {$[44]$} \\
\hline Piper nigrum & Powder & Piperine & Copper sulphate & $60,30 \mathrm{~min}$ & Antibacterial & {$[44]$} \\
\hline Syzygium cumin & Leaves & $\begin{array}{l}\text { Anthocyanin, glucoside, } \\
\text { isoquercetin }\end{array}$ & $\begin{array}{l}0.1 \mathrm{M} \text { Copper } \\
\text { sulphate }\end{array}$ & $100,30 \mathrm{~min}$ & Antibacterial & [45] \\
\hline Mitragyna parvifolia & Bark & Alkaloid & Copper sulphate & $80,4-5 \mathrm{~h}$ & Antibacterial & [46] \\
\hline Cissus arnotiana & Leaves & $\begin{array}{l}\text { Saponins, flavonoids, } \\
\text { alkaloids, steroids, } \\
\text { anthraquinones }\end{array}$ & $\begin{array}{l}10 \text { mmol Copper } \\
\text { sulphate }\end{array}$ & $\mathrm{RT}, 4 \mathrm{~h}$ & $\begin{array}{l}\text { Antibacterial, } \\
\text { antioxidant }\end{array}$ & {$[47]$} \\
\hline Capparis spinosa & Fruit & Flavonoids, proteins & $\begin{array}{l}0.01 \text { M Copper } \\
\text { sulphate }\end{array}$ & $60,24 \mathrm{~h}$ & Antinociceptive & [48] \\
\hline Garcinia mangostana & Leaves & Tannins & $\begin{array}{l}0.001 \mathrm{M} \text { Copper } \\
\text { nitrate }\end{array}$ & $70,1 \mathrm{~h}$ & Antibacterial & [49] \\
\hline Quisqualis indica & Flower & Alkaloid, flavonoid & Copper acetate & RT, Nil & Anticancer & {$[50]$} \\
\hline Gnidia glauca & $\begin{array}{l}\text { Flower, } \\
\text { stem and } \\
\text { leaf }\end{array}$ & $\begin{array}{l}\text { Alkaloids, steroids, } \\
\text { saponins, coumarin, } \\
\text { flavonoids }\end{array}$ & $\begin{array}{l}1 \text { mmol Copper } \\
\text { sulphate }\end{array}$ & $100,5 \mathrm{~h}$ & Antidiabetic & [51] \\
\hline Plumbago zeylanica & Leaves & $\begin{array}{l}\text { Flavonoids, alkaloids, } \\
\text { steroids, tannins, phenols }\end{array}$ & $\begin{array}{l}1 \text { mmol Copper } \\
\text { sulphate }\end{array}$ & $100,5 \mathrm{~h}$ & Antidiabetic & {$[51]$} \\
\hline $\begin{array}{l}\text { Syzygium } \\
\text { alternifolium }\end{array}$ & Stem bark & $\begin{array}{l}\text { Anthocyanins, glucose, } \\
\text { ellagic acid, isoquercetin }\end{array}$ & $\begin{array}{l}5 \text { mmol Copper } \\
\text { sulphate }\end{array}$ & $50,2 \mathrm{~h}$ & $\begin{array}{l}\text { Antibacterial, } \\
\text { antifungal, } \\
\text { anticancer }\end{array}$ & {$[52]$} \\
\hline Ctenolepis garcinii & Powder & $\begin{array}{l}\text { Anthocyanin, alkaloids, } \\
\text { steroids, tannins, saponins, } \\
\text { flavonoids }\end{array}$ & $\begin{array}{l}1 \text { mmol Copper } \\
\text { nitrate }\end{array}$ & $\mathrm{RT}, 24 \mathrm{~h}$ & Antibacterial & {$[53]$} \\
\hline Blumea balsamifera & Leaves & $\begin{array}{l}\text { Terpenes, flavonoids, } \\
\text { esters, alcohol, sterol }\end{array}$ & $\begin{array}{l}1 \text { mmol Copper } \\
\text { sulphate }\end{array}$ & $100,8 \mathrm{~h}$ & Antibacterial & {$[54]$} \\
\hline Prosopis cineraria & Leaves & $\begin{array}{l}\text { Alkaloids, flavonoids, } \\
\text { tannins, saponins }\end{array}$ & $\begin{array}{l}5 \text { mmol Copper } \\
\text { acetate }\end{array}$ & $-20,10 \mathrm{~min}$ & $\begin{array}{l}\text { Antibacterial, } \\
\text { anticancer }\end{array}$ & [55] \\
\hline $\begin{array}{l}\text { Cinnamomum } \\
\text { zeylanicum }\end{array}$ & Bark & $\begin{array}{l}\text { Tannins, mucilage, calcium } \\
\text { oxalate, starch }\end{array}$ & $\begin{array}{l}100 \mathrm{mmol} \\
\text { Copper sulphate }\end{array}$ & 60-100, Nil & Antibacterial & {$[56]$} \\
\hline
\end{tabular}




\begin{tabular}{|c|c|c|c|c|c|c|}
\hline Plant name & Parts used & Phyto constituents & Precursor & Temp $\left({ }^{\circ} \mathrm{C}\right) /$ time & Activity & References \\
\hline Bougainvillea & Flower & Phenol, flavonoid, saponin & Copper acetate & $80,10 \mathrm{~min}$ & Antifungal & {$[57]$} \\
\hline Citrus reticulate & Peel & Limonene, myrcene & $\begin{array}{l}0.001 \mathrm{M} \text { Copper } \\
\text { sulphate }\end{array}$ & 45, Nil & Antibacterial & [58] \\
\hline Olea europea & Leaves & $\begin{array}{l}\text { Flavonoids, steroids, } \\
\text { tannins, terpenes }\end{array}$ & $\begin{array}{l}2 \text { mmol copper } \\
\text { sulphate }\end{array}$ & $100,24 \mathrm{~h}$ & $\begin{array}{l}\text { Anticancer, } \\
\text { antioxidant }\end{array}$ & [59] \\
\hline $\begin{array}{l}\text { Artemesia } \\
\text { haussknechtii }\end{array}$ & Leaves & $\begin{array}{l}\text { Fibre, protein, tannin, } \\
\text { tocopherol }\end{array}$ & $\begin{array}{l}0.01 \mathrm{M} \text { Copper } \\
\text { sulphate }\end{array}$ & RT, $24 \mathrm{~h}$ & $\begin{array}{l}\text { Antibacterial, } \\
\text { antioxidant }\end{array}$ & {$[60]$} \\
\hline Leucas aspera & Leaves & Phenols, proteins, tannins & Copper sulphate & $100,2 \mathrm{~h}$ & Antibacterial & [61] \\
\hline Morinda tinctoria & Leaves & $\begin{array}{l}\text { Proteins and amino acids, } \\
\text { diterpenes }\end{array}$ & Copper sulphate & $100,2 \mathrm{~h}$ & Antibacterial & {$[61]$} \\
\hline Morus alba & Leaves & $\begin{array}{l}\text { Protein, saccharose, xylose, } \\
\text { galactose }\end{array}$ & Copper acetate & $60,5 \mathrm{~min}$ & Antioxidant & [62] \\
\hline Avicennia mariana & Leaves & $\begin{array}{l}\text { Triterpenoids, } \\
\text { hydrocarbons }\end{array}$ & Copper sulphate & $65,3 \mathrm{~h}$ & $\begin{array}{l}\text { Antibacterial, } \\
\text { antifungal }\end{array}$ & [63] \\
\hline Datura stramonium & Leaves & Tropane alkaloids & Copper sulphate & $65,3 \mathrm{~h}$ & $\begin{array}{l}\text { Antibacterial, } \\
\text { antifungal }\end{array}$ & [63] \\
\hline $\begin{array}{l}\text { Eucalyptus } \\
\text { camaldulensis }\end{array}$ & Leaves & $\begin{array}{l}\text { Aromatic phenol, alcohol, } \\
\text { oxides, esters }\end{array}$ & Copper sulphate & $65,3 \mathrm{~h}$ & $\begin{array}{l}\text { Antibacterial, } \\
\text { antifungal }\end{array}$ & [63] \\
\hline Rosa rubiginosa & Leaves & $\begin{array}{l}\text { Proteins, flavonoids, } \\
\text { tocopherol }\end{array}$ & Copper sulphate & $65,3 \mathrm{~h}$ & $\begin{array}{l}\text { Antibacterial, } \\
\text { antifungal }\end{array}$ & [63] \\
\hline Stachys lavandulifolia & Flower & $\begin{array}{l}\text { Alpha pinene, linalool, } \\
\text { acetoside }\end{array}$ & Copper chloride & RT, Nil & Antibacterial & {$[64]$} \\
\hline $\begin{array}{l}\text { Echinops } \\
\text { sphaerocephalus }\end{array}$ & Roots & $\begin{array}{l}\text { Apigenin, hesperidin, } \\
\text { kaempferol, rutin }\end{array}$ & $\begin{array}{l}0.5 \mathrm{M} \text { Copper } \\
\text { nitrate }\end{array}$ & RT, Nil & Antibacterial & {$[65]$} \\
\hline $\begin{array}{l}\text { Cardiospermum } \\
\text { helicacabum }\end{array}$ & Leaves & $\begin{array}{l}\text { Saponin, phytosterol, } \\
\text { polyphenol }\end{array}$ & $\begin{array}{l}10 \text { mmol Copper } \\
\text { chloride }\end{array}$ & $90,1 \mathrm{~h}$ & Antibacterial & [66] \\
\hline Asparagus adscendens & $\begin{array}{l}\text { Root and } \\
\text { leaf }\end{array}$ & Steroidal saponins & $\begin{array}{l}1 \text { mmol Copper } \\
\text { sulphate }\end{array}$ & RT, $1 \mathrm{~h}$ & Antibacterial & {$[67]$} \\
\hline Passiflora foetida & Leaves & $\begin{array}{l}\text { Amino acid alpha alanine, } \\
\text { organic acids }\end{array}$ & $\begin{array}{l}20 \text { mmol copper } \\
\text { sulphate }\end{array}$ & $80,4 \mathrm{~h}$ & Antibacterial & [68] \\
\hline Majorana hortensis & Leaves & Monoterpenes & Copper chloride & $70,24 \mathrm{~h}$ & Antibacterial & [69] \\
\hline Magnolia champaca & Flower & Phenol, phenyl acetonitrile & $\begin{array}{l}3 \text { mmol copper } \\
\text { acetate }\end{array}$ & $37,24 \mathrm{~h}$ & Antioxidant & {$[70]$} \\
\hline Citrus aurantifolia & Leaves & Terpenes & Copper sulphate & $80,10 \mathrm{~h}$ & Antibacterial & [71] \\
\hline Capparis spinosa & Fruit & $\begin{array}{l}\text { Alkaloids, flavonoids, } \\
\text { phenolics, triterpenoids, } \\
\text { steroids }\end{array}$ & Copper sulphate & $60,24 \mathrm{~h}$ & Antibacterial & {$[72]$} \\
\hline $\begin{array}{l}\text { Terminalia chebula, } \\
\text { Terminalia belerica, } \\
\text { Emblica officinalis }\end{array}$ & Fruits & Phenols & $\begin{array}{l}1 \text { mmol Copper } \\
\text { sulphate }\end{array}$ & $37,5 \mathrm{~h}$ & $\begin{array}{l}\text { Antibacterial, } \\
\text { antifungal }\end{array}$ & [73] \\
\hline
\end{tabular}
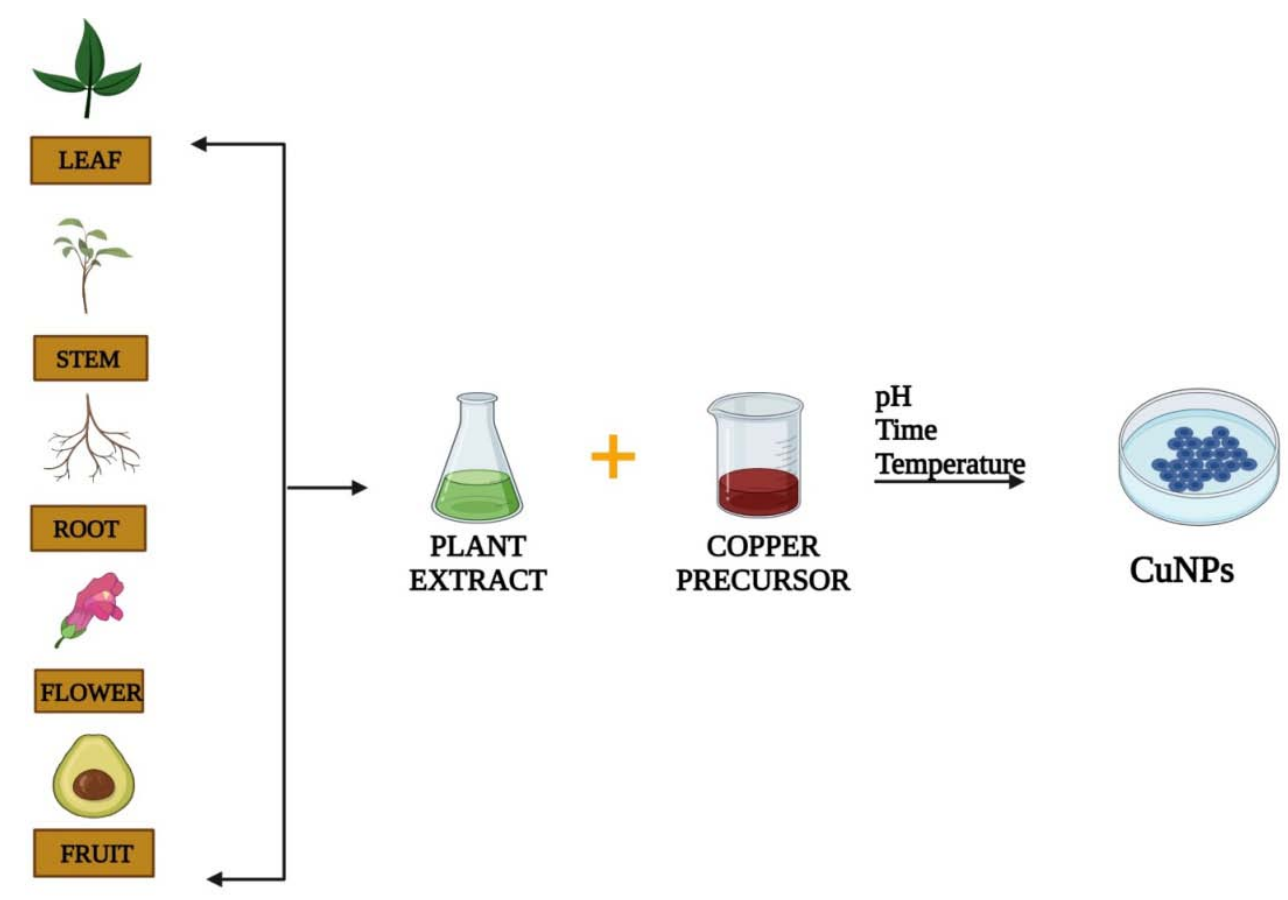

Fig. 6: Plant mediated synthesis of copper nanoparticles 
Table 2: Bacteria mediated synthesis of copper nanoparticles

\begin{tabular}{|c|c|c|c|}
\hline Bacteria & Precursor & Temp $\left({ }^{\circ} \mathrm{C}\right) /$ time & Reference \\
\hline Staphylococcus aureus & 0.5 M Copper sulphate & RT, Nil & [8] \\
\hline Staphylococcus epidermis & 0.5 M Copper sulphate & RT, Nil & [8] \\
\hline Streptomyces griseus & $1 \mathrm{mmol}$ Copper sulphate & $37,72 \mathrm{~h}$ & [76] \\
\hline Escherichia coli & Copper sulphate & $30,1 \mathrm{~h}$ & [83] \\
\hline Morganella morgana & Copper sulphate & $30,24-48 \mathrm{~h}$ & {$[84]$} \\
\hline Bacillus Euplotes focardii & 4 mmol Copper sulphate & $\mathrm{RT}, 48 \mathrm{~h}$ & [87] \\
\hline Brevundimonas Euplotes focardii & $5 \mathrm{mmol}$ Copper sulphate & $\mathrm{RT}, 48 \mathrm{~h}$ & [87] \\
\hline Marinomonas Euplotes focardii & 5 mmol Copper sulphate & $\mathrm{RT}, 48 \mathrm{~h}$ & [87] \\
\hline Pseudomonas Euplotes focardii & $3.5 \mathrm{mmol}$ Copper sulphate & $\mathrm{RT}, 48 \mathrm{~h}$ & [87] \\
\hline Rhodococcus Euplotes focardii & 4.5 mmol Copper sulphate & $\mathrm{RT}, 48 \mathrm{~h}$ & [87] \\
\hline Pseudomonas fluorescens & $1 \mathrm{mmol}$ Copper sulphate & $35,48 \mathrm{~h}$ & [92] \\
\hline
\end{tabular}

Table 3: Fungi mediated synthesis of copper nanoparticles

\begin{tabular}{|c|c|c|c|}
\hline Fungi & Precursor & Temp $\left({ }^{\circ} \mathrm{C}\right) /$ Time & Reference \\
\hline Candida albicans & 0.5 M Copper sulphate & RT, Nil & [8] \\
\hline Candida parapsilosis & $0.5 \mathrm{M}$ Copper sulphate & RT, Nil & [8] \\
\hline Aspergillus versicolor & Copper sulphate & $25,72 \mathrm{~h}$ & [12] \\
\hline Fusarium solani & Copper sulphate & $95,90 \mathrm{~min}$ & [74] \\
\hline Neofusicoccum sp. & Copper sulphate & $95,90 \mathrm{~min}$ & [74] \\
\hline Fusarium oxysporum & Copper sulphate & $95,90 \mathrm{~min}$ & [74] \\
\hline Botrytis cinerea & Copper oxide (purchased) & $22,7-14 \mathrm{~d}$ & [77] \\
\hline Candida albicans & $0.01 \mathrm{M}$ Copper acetate & $140,10 \mathrm{~h}$ & [78] \\
\hline Penicillium olsonii & 0.02 M Copper sulphate & $25,3 \mathrm{~d}$ & [78] \\
\hline Fusarium sp. & Copper chloride & 80 , Nil & [79] \\
\hline Fusarium culmorum & 0.001-0.0100 M Copper nitrate & $28 \pm 2,72 \mathrm{~h}$ & [80] \\
\hline Fusarium oxysporum & 0.001-0.0100 M Copper nitrate & $28 \pm 2,72 \mathrm{~h}$ & [80] \\
\hline Fusarium equiseti & 0.001-0.0100 M Copper nitrate & $28 \pm 2,72 \mathrm{~h}$ & [80] \\
\hline Aspergillus flavus & $100 \mathrm{mmol}$ Copper sulphate & $20,20 \mathrm{~min}$ & [81] \\
\hline Coniophora puteana & Cupric carbonate. Copper hydroxide & $20,14 \mathrm{~d}$ & [82] \\
\hline Gleophyllum trabeum & Cupric carbonate. Copper hydroxide & $20,14 \mathrm{~d}$ & [82] \\
\hline Trametes versicolor & Cupric carbonate. Copper hydroxide & $20,14 \mathrm{~d}$ & [82] \\
\hline Agaricus bisporus & $1 \mathrm{mmol}$ Copper nitrate & $60,20 \mathrm{~min}$ & [85] \\
\hline
\end{tabular}

Table 4: Characterization of the biosynthesized CuNPs

\begin{tabular}{|c|c|c|c|c|c|}
\hline Plants/Organisms & Characterization & Size (nm) & Shape & $\lambda \max (\mathrm{nm})$ & References \\
\hline Allium sativum & UV-VIS, FTIR, XRD, SEM, TEM & 100 & Spherical & 580 & [1] \\
\hline Allium sativum & UV-VIS, FTIR, XRD, TEM & $10-40$ & Spherical & 575 & {$[4]$} \\
\hline Zingiber officinale & UV-VIS, FTIR, XRD, TEM & $25-50$ & Spherical & 610 & [4] \\
\hline Cissus quadrangularis & UV-VIS, FTIR, XRD, SEM, TEM, EDX & $33 \pm 2$ & Spherical & 260 & [10] \\
\hline Moringa oleifera & UV-VIS, FTIR, XRD, TEM, HRTEM & $35.8-49.2$ & Spherical & 260 & [13] \\
\hline Azadirachta indica & UV-VIS, XRD, SEM, TEM, SAED. EDX & 12 & Spherical & $220-235$ & {$[14]$} \\
\hline Hibiscus rosasinensis & UV-VIS, XRD, SEM, TEM, SAED, EDX & 12 & Spherical & $220-235$ & {$[14]$} \\
\hline Murraya koenigii & UV-VIS, XRD, SEM, TEM, SAED, EDX & 12 & Spherical & $220-235$ & {$[14]$} \\
\hline Tamarindus indica & UV-VIS, XRD, SEM, TEM, SAED, EDX & 12 & Spherical & $220-235$ & {$[14]$} \\
\hline Eclipta prostata & UV-VIS, FTIR, XRD, SEM, HRTEM, SAED & $28-50$ & $\begin{array}{l}\text { Spherical, } \\
\text { Hexagonal, } \\
\text { Cubical }\end{array}$ & 565 & [15] \\
\hline Abutilon indicum & FTIR, XRD, SEM, EDX & $<100$ & Spherical & - & {$[16]$} \\
\hline Clerodendrum inerme & FTIR, XRD, SEM, EDX & $<100$ & Spherical & - & [16] \\
\hline Clerodendrum infortunatum & FTIR, XRD, SEM, EDX & $<100$ & Spherical & - & [16] \\
\hline Eryngium caucasicum & UV-VIS, FTIR, XRD, SEM & 40 & Spherical & 580 & [17] \\
\hline Curcuma longa & $\begin{array}{l}\text { UV-VIS, FTIR, XRD, SEM, TEM, }{ }^{1} \text { HNMR, } \\
{ }^{13} \text { CNMR }\end{array}$ & $20-30$ & Spherical & 436 & [18] \\
\hline Vaccinium myrtillus & TEM, UV-VIS, XPS & $2-10$ & Tiny globular & $540-550$ & [19] \\
\hline Vaccinium uliginosum & TEM, UV-VIS, XPS & $2-10$ & Tiny globular & $550-565$ & [19] \\
\hline Cucumis sativus & SEM, XRF & $10-30$ & Spherical & - & [20] \\
\hline Anethum graveolens & SEM, FTIR & $100-250$ & Spherical & - & [21] \\
\hline Thymus daenensis & SEM, FTIR & $100-250$ & Spherical & - & [21] \\
\hline Persea Americana & UV-VIS, FTIR, XRD, SEM,TEM & $45-100$ & Spherical & 357 & {$[22]$} \\
\hline Trigonella foenum-graecum & UV-VIS, FTIR, XRD, TEM, DLS & $31.7-35$ & Spherical & 400 & [23] \\
\hline Punica granatum & UV-VIS, FTIR, TEM, PSA & $15-20$ & Spherical & 585 & [24] \\
\hline Fagus sylvatica & TEM & 15.6 & Spherical & - & [25] \\
\hline Pinus sylvestris & TEM & 15.6 & Spherical & - & {$[25]$} \\
\hline Cissus vitiginea & UV-VIS, FTIR, XRD, SEM, TEM, AFM, XPS & 20 & Spherical & 340 & [26] \\
\hline Citrus medica & UV-VIS, XRD & 33 & Spherical & 631 & {$[27]$} \\
\hline Azadirachta indica & UV-VIS, FTIR, XRD, SEM, TEM & 100 & Spherical & 260 & [29] \\
\hline Ocimum sanctum & UV-VIS, FTIR, TEM, HRTEM, PSA, SAED & 25 & Cylindrical, rod & 345 & [30] \\
\hline
\end{tabular}




\begin{tabular}{|c|c|c|c|c|c|}
\hline Plants/Organisms & Characterization & Size (nm) & Shape & $\lambda \max (\mathrm{nm})$ & References \\
\hline Allium saralicum & UV-VIS, FTIR, FESEM, TEM, AFM & $45-50$ & $\begin{array}{l}\text { and elliptical } \\
\text { Spherical }\end{array}$ & 576 & [31] \\
\hline Allium eriophyllum & UV-VIS, FTIR, XRD, FESEM,TEM & $30-35$ & Spherical & 572 & {$[32]$} \\
\hline Zingiber officinale & UV-VIS, FTIR, XRD, TEM, NTA & 50 & Spherical & 618 & [33] \\
\hline Celastrus paniculatus & UV-VIS, FTIR, SEM-EDX, TEM, DLS & $2-10$ & Spherical & 269 & [34] \\
\hline Triticum aestivum & SEM, DLS & $15.6 \mu \mathrm{m}$ & Spherical & - & [35] \\
\hline Tilia cordata & UV-VIS, FTIR, XRD, SEM, TEM & $4.7-17.4$ & Spherical & 563 & [36] \\
\hline Syzygium aromaticum & UV-VIS, FTIR, XRD, FESEM, TEM & 15 & Spherical & 580 & [37] \\
\hline Falcaria vulgaris & UV-VIS, FTIR, XRD, FESEM, TEM & $20-25$ & Spherical & 572 & [38] \\
\hline Camellia sinensis & UV-VIS, FTIR, SEM, EDX & $10-20$ & Spherical & $563-582$ & [39] \\
\hline Manilkara zapota & UV-VIS, FTIR, XRD, SEM, EDX & $18.9-42.5$ & Spherical & 580 & {$[40]$} \\
\hline Citrus limon & UV-VIS, FTIR, XRD, SEM, TEM & 28 & Spherical & 579 & [41] \\
\hline Zizipus spinachristi & UV-VIS, FTIR, XRD, FESEM, TEM & $5-20$ & Spherical & 551 & [42] \\
\hline Piper retrofractum & UV-VIS, FTIR, XRD, SEM-EDX, TEM & $2-10$ & Spherical & 207 & [43] \\
\hline Piper longum & UV-VIS, FTIR, XRD, FESEM, TEM, EDX & $15-30$ & Spherical & 225 & [44] \\
\hline Piper nigrum & UV-VIS, FTIR, XRD, FESEM, TEM, EDX & $15-30$ & Spherical & 245 & {$[44]$} \\
\hline Syzygium cumin & UV-VIS, FTIR, XRD, SEM, EDX & $10 \mu \mathrm{m}$ & Spherical & 190 & [45] \\
\hline Mitragyna parvifolia & UV-VIS, FTIR, XRD, SEM, TEM & $12-23$ & Spherical & $565-570$ & [46] \\
\hline Cissus arnotiana & UV-VIS, XRD, SEM, TEM & $60-90$ & Spherical & $350-380$ & [47] \\
\hline Capparis spinosa & UV-VIS, FTIR, SEM, EDX & $17-41$ & Spherical & 414 & [48] \\
\hline Garcinia mangostana & XRD, SEM, TEM, TGA, DTA & $20-25$ & Spherical & - & [49] \\
\hline Quisqualis indica & UV-VIS, XRD, FESEM, TEM, AFM & $39.3 \pm 5.45$ & Spherical & 309 & [50] \\
\hline Gnidia glauca & UV-VIS, FTIR, XRD, FESEM, DLS & $1-5$ & Spherical & 550 & [51] \\
\hline Plumbago zeylanica & UV-VIS, FTIR, XRD, FESEM, DLS & $1-5$ & Spherical & 600 & [51] \\
\hline Syzygium alternifolium & UV-VIS, FTIR, XRD, TEM, DLS & $5-13$ & Spherical & 285 & [52] \\
\hline Ctenolepis garcinii & UV-VIS, FTIR, XRD, SEM, EDX & $67-82$ & Spherical & 330 & [53] \\
\hline Blumea balsamifera & FTIR, SEM, EDX & $1 \mu \mathrm{m}$ & Spherical & - & [54] \\
\hline Prosopis cineraria & UV-VIS, FTIR, XRD, FESEM, EDX & $18.9-32.09$ & Spherical & 420 & [55] \\
\hline Cinnamomum zeylanicum & UV-VIS, FTIR, TEM & 66.14 & Spherical & 252.55 & [56] \\
\hline Bougainvillea & UV-VIS, FTIR, XRD, TEM & $12 \pm 4$ & Spherical & 274 & {$[57]$} \\
\hline Citrus reticulate & UV-VIS, FTIR, XRD, TEM, DLS & $54-72$ & Spherical & 442 & [58] \\
\hline Olea europea & FTIR, XRD, SEM, TEM & $20-50$ & Spherical & - & [59] \\
\hline Artemesia haussknechtii & UV-VIS, FTIR, XRD, FESEM, AFM, EDX & $35.36 \pm 444$ & Spherical & $200-300$ & [60] \\
\hline Leucas aspera & UV-VIS, FTIR, XRD, SEM & $30-32$ & Spherical & 319 & [61] \\
\hline Morinda tinctoria & UV-VIS, FTIR, XRD, SEM & $18-72$ & Spherical & 412 & {$[61]$} \\
\hline Morus alba & UV-VIS, FTIR, XRD, TEM, SEM & $40-50$ & Spherical & 285 & [62] \\
\hline Avicennia mariana & UV-VIS, FTIR, SEM, TEM,EDX & 64 & Spherical & $563-582$ & [63] \\
\hline Datura stramonium & UV-VIS, FTIR, SEM, TEM,EDX & 43 & Spherical & $563-582$ & [63] \\
\hline Eucalyptus camaldulensis & UV-VIS, FTIR, SEM, TEM,EDX & 65 & Near spherical & $563-582$ & [63] \\
\hline Rosa rubiginosa & UV-VIS, FTIR, SEM, TEM,EDX & 55 & Spherical & $563-582$ & [63] \\
\hline Stachys lavandulifolia & UV-VIS, FTIR, XRD, TEM & $80 \pm 8$ & Spherical & 590 & [64] \\
\hline Echinops sphaerocephalus & UV-VIS, FTIR, XRD, FESEM & $20-100$ & Spherical & 441 & [65] \\
\hline Cardiospermum helicacabum & UV-VIS, FTIR, XRD, FESEM, TEM, DLS & $30-40$ & Spherical & 553 & [66] \\
\hline Asparagus adscendens & UV-VIS, FTIR, HRTEM, SAED & $50-60$ & Spherical & $500-700$ & [67] \\
\hline Passiflora foetida & UV-VIS, FTIR, XRD, SEM, EDX & 40 & Spherical & 407 & [68] \\
\hline Majorana hortensis & UV-VIS, FTIR, XRD, SEM, EDX & 3 & $\begin{array}{l}\text { Irregular, } \\
\text { agglomerated } \\
\text { particles }\end{array}$ & 280 & [69] \\
\hline Magnolia champaca & UV-VIS, FTIR, XRD, SEM, TEM, EDX & $20-40$ & Spherical & 285 & [70] \\
\hline Citrus aurantifolia & UV-VIS, FTIR, XRD, SEM & $20-90$ & Spherical & $240-300$ & [71] \\
\hline Capparis spinosa & UV-VIS, FTIR, SEM, EDX & $17-41$ & Spherical & 414 & [72] \\
\hline $\begin{array}{l}\text { Terminalia chebula, Terminalia } \\
\text { belerica, Emblica officinalis }\end{array}$ & XRD, SEM & $20-25$ & Spherical & - & [73] \\
\hline $\begin{array}{l}\text { Staphylococcus aureus, } \\
\text { Staphylococcus epidermis, } \\
\text { Candida albicans, } \\
\text { Candida parapsilosis }\end{array}$ & UV-VIS, XPS, DLS, NTA & $50-70$ & Spherical & 550 & [8] \\
\hline Aspergillus versicolor & UV-VIS, FTIR, SEM, TEM, DLS & $22.09 \pm 0.6$ & $\begin{array}{l}\text { Round, } \\
\text { polygonal }\end{array}$ & 460 & [12] \\
\hline $\begin{array}{l}\text { Fusarium solani, } \\
\text { Neofusicoccum sp, } \\
\text { Fusarium oxysporum }\end{array}$ & XRD, TEM, PDF, XPS & $200-500$ & Spherical & - & {$[74]$} \\
\hline Streptomyces griseus & UV-VIS, FTIR, XRD, TEM & $5-50$ & Spherical & 590 & [76] \\
\hline Botrytis cinerea & TEM & $40-100$ & Spherical & - & [77] \\
\hline Candida albicans & XRD, FESEM, HRTEM & 10.7 & Spherical & - & [78] \\
\hline Penicillium olsonii & UV-VIS, FTIR, SEM & $6-26$ & Spherical & 631 & [78] \\
\hline Fusrium sp. & UV-VIS, FTIR, XRD, TEM & $20-50$ & Spherical & $500-600$ & [79] \\
\hline $\begin{array}{l}\text { Fusarium culmorum, } \\
\text { Fusarium oxysporum, } \\
\text { Fusarium equiseti }\end{array}$ & UV-VIS, FTIR, XRD, TEM & $3-30$ & Spherical & 560 & {$[80]$} \\
\hline Aspergillus flavus & UV-VIS, FTIR, XRD, TEM, NTA & $5-12$ & Spherical & 602 & [81] \\
\hline $\begin{array}{l}\text { Coniophora puteana, } \\
\text { Gleophyllum trabeum, }\end{array}$ & UV-VIS, XRD, TEM, SAD, EDX & $15-20$ & Spherical & 360 & [82] \\
\hline
\end{tabular}




\begin{tabular}{|c|c|c|c|c|c|}
\hline Plants/Organisms & Characterization & Size (nm) & Shape & $\lambda \max (\mathrm{nm})$ & References \\
\hline \multicolumn{6}{|l|}{ Trametes versicolor } \\
\hline Escherichia coli & SEM, EDX & $10-50$ & Spherical & - & {$[83]$} \\
\hline Morganella morgana & UV-VIS, FTIR, XRD, SEM, EDX & $13.5 \pm 0.6$ & Spherical & 540 & [84] \\
\hline Agaricus bisporus & UV-VIS, FTIR, XRD, SEM, TEM, EDX & 10 & Spherical & 551 & [85] \\
\hline Spirulina platansis & UV-VIS, FTIR, XRD, SEM & 5 & Crystal & 641 & [87] \\
\hline Bacillus Euplotes focardii & UV-VIS, FTIR, XRD, TEM, DLS & $10-70$ & $\begin{array}{l}\text { Monodispersed, } \\
\text { spherical, oval }\end{array}$ & $381-383$ & [87] \\
\hline $\begin{array}{l}\text { Brevundimonas Euplotes } \\
\text { focardii }\end{array}$ & UV-VIS, FTIR, XRD, TEM, DLS & $10-70$ & $\begin{array}{l}\text { Monodispersed, } \\
\text { spherical, oval }\end{array}$ & $381-383$ & [87] \\
\hline $\begin{array}{l}\text { Marinomonas Euplotes } \\
\text { focardii }\end{array}$ & UV-VIS, FTIR, XRD, TEM, DLS & $10-70$ & $\begin{array}{l}\text { Monodispersed, } \\
\text { spherical, oval }\end{array}$ & $381-383$ & [87] \\
\hline $\begin{array}{l}\text { Pseudomonas Euplotes } \\
\text { focardii }\end{array}$ & UV-VIS, FTIR, XRD, TEM, DLS & $10-70$ & $\begin{array}{l}\text { Monodispersed, } \\
\text { spherical, oval }\end{array}$ & $381-383$ & [87] \\
\hline Rhodococcus Euplotes focardii & UV-VIS, FTIR, XRD, TEM, DLS & $10-70$ & $\begin{array}{l}\text { Monodispersed, } \\
\text { spherical, oval }\end{array}$ & $381-383$ & [87] \\
\hline Pseudomonas fluorescens & UV-VIS, FTIR, XRD, TEM & $15.6-34.2$ & Spherical & $420-560$ & {$[92]$} \\
\hline Scenedesmus obliquus & SEM, AFM & 100 & Spherical & - & [95] \\
\hline
\end{tabular}

Note: UV-VIS, Ultra Violet Visible Spectroscopy; FTIR, Fourier Transform Infrared Spectroscopy; SEM, Scanning Electron Microscopy; FESEM, Field Emission Scanning Electron Microscopy; TEM, Transmission Electron Microscopy; HRTEM, High-Resolution Transmission Electron Microscopy; DLS, Dynamic Light Scattering; ZP, Zeta Potential; PSA, Particle Size Analyzers; XRD, X-Ray Diffraction; XPS, X-Ray Photon Spectroscopy; XRF, X-Ray Fluorescence; EDX, Energy Dispersive X-Ray; AFM, Atomic Force Microscopy; TGA, Thermogravimetric Analysis; SAED, Selected Area Electron Diffraction; VSM, Vibrating Sample Magnetometer; NTA, Nanoparticle Tracking Analysis.

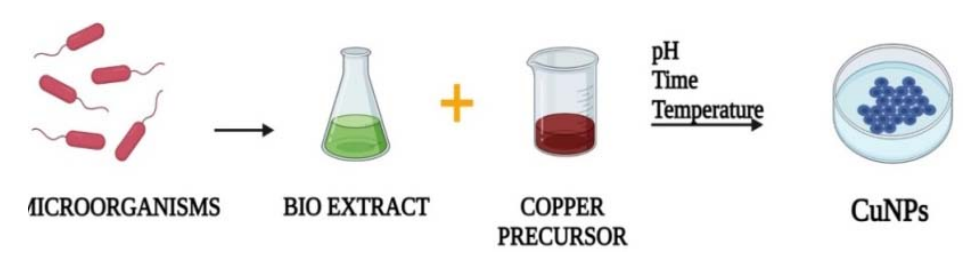

Fig. 7: Microorganisms mediated synthesis of copper nanoparticles

\section{Characterization}

The primary step of characterization after the synthesis of CuNPs was to determine the size, shape and morphology of the synthesized nanoparticles. The crystal structure and the chemical composition of the synthesized nanoparticles were analyzed by using various analytical techniques. The techniques like Scanning electron microscopy (SEM), Field emission scanning electron microscopy (FESEM), Transmission electron microscopy (TEM), High-resolution transmission electron microscopy (HRTEM), Dynamic light scattering (DLS), Zeta potential (ZP), Particle size analyzers (PSA) were used to determine their morphology. The various spectral, thermal and other techniques like UV-Vis spectroscopy (UV-Vis), Fourier transform infrared spectroscopy (FTIR), X-Ray diffraction (XRD), X-Ray Photon spectroscopy (XPS), X-Ray fluorescence (XRF), Atomic force microscopy (AFM), Thermogravimetric analysis (TGA), Energy-dispersive X-ray (EDX), Selected area electron diffraction (SAED), Vibrating sample magnetometer (VSM) and Nanoparticle tracking analysis (NTA) were used to determine the elemental composition and other features of the synthesized CuNPs. Based on the previous studies, CuNPs exhibited the size between the range of 1-250 $\mathrm{nm}$ with spherical, oval, tiny globular, cylindrical, irregular, polygonal, hexagonal, rod, elliptical, agglomerated and monodispersive shapes. All the synthesized CuNPs showed their excitation at the range between $190-631 \mathrm{~nm}$. The characterization results of the synthesized CuNPs are given in table 4.

\section{Biological applications}

Copper nanoparticles are most commonly used in the emerging interdisciplinary field of nanobiotechnology and in biomedical technology. CuNPs have extensive applications in various fields due to their constant renewable surface, nontoxic and low cost of preparation [88, 89]. This review suggests that CuNPs can act as antioxidant, anticancer, antibacterial, antifungal, anti-diabetic, antinociceptive and wound healing agents (fig. 8).

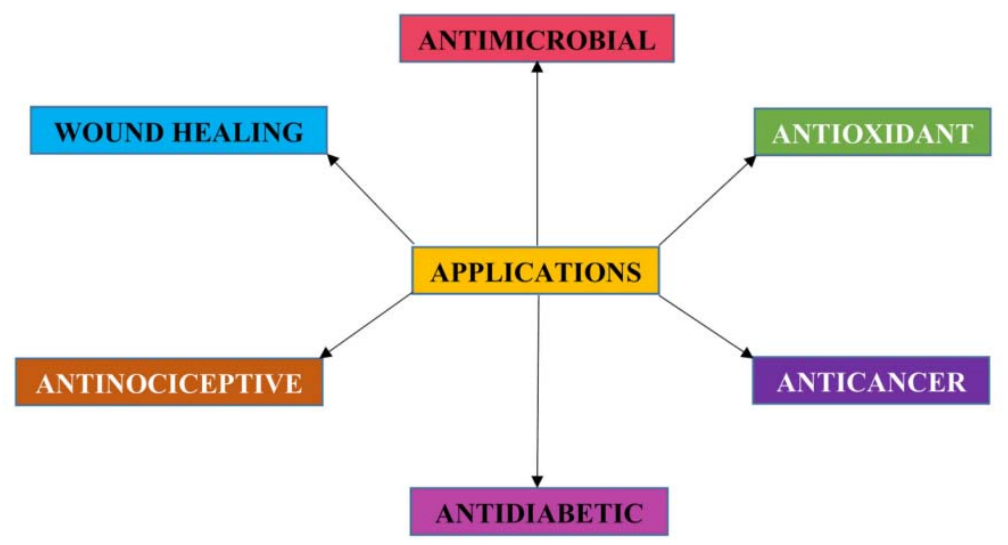

Fig. 8: Biological applications of copper nanoparticles 


\section{Antibacterial activity}

Gram-positive and Gram-negative bacteria are distinguished by the structure of their cell walls. Gram-positive bacteria have a thick peptidoglycan layer in their cell wall, whereas Gram-negative bacteria have a thin peptidoglycan layer with a periplasm membrane layer. Due to the difference in cell walls, Gram-positive bacteria develop resistance to the nanoparticle's mechanism. CuNPs had a superior antibacterial effect against the causative agents. For analysing the anti-bacterial activity of the synthesised copper nanoparticles, the zone of inhibition is to be considered [90,91]. CuNPs generated from the various plant extracts showed greater activity against pathogens such as Bacillus subtilis, Escherichia coli, Klebsiella sp., Pseudomonas aeruginosa and Staphylococcus aureus. The susceptible organisms and the zone of inhibition are shown in table 5 .

Table 5: Antibacterial activity of biosynthesized CuNPs

\begin{tabular}{|c|c|c|c|c|c|}
\hline Plant extracts & Tested organisms & Media/Assay used & $\begin{array}{l}\text { Concentration } \\
(\mu \mathrm{g} / \mathrm{ml})\end{array}$ & $\begin{array}{l}\text { Diameter of zone of } \\
\text { inhibition }(\mu \mathrm{g} / \mathrm{ml}) \\
\text { /inhibition }(\%)\end{array}$ & References \\
\hline Trigonella foenum-graecum & $\begin{array}{l}\text { Acinetobacter } \\
\text { calcoaceticus }\end{array}$ & Agar well diffusion method & 62.0 & $15.0 \pm 0.5$ & [23] \\
\hline Eryngium caucasicum & Bacillus cereus & Agar diffusion method & 60 & 21.1 & [17] \\
\hline Syzygium aromaticum & Bacillus sp. & Kirby-Bauer disc diffusion assay & 16 & 8 & [37] \\
\hline Allium sativum & Bacillus subtilis & Agar well diffusion method & 75 & 18 & [1] \\
\hline Clerodendrum inerme & & Agar well diffusion method & 0.08 & 0.04 & [16] \\
\hline Trigonella foenum-graecum & & Agar well diffusion method & 62.0 & $13.0 \pm 0.1$ & [23] \\
\hline Allium saralicum & & Agar well diffusion method & 64 & $43.4 \pm 0.89$ & [31] \\
\hline Allium eriophyllum & & Disc diffusion method & 64 & $34.2 \pm 0.83$ & [32] \\
\hline Falcaria vulgaris & & Disc diffusion method & 64 & $26.6 \pm 0.89$ & [38] \\
\hline Piper longum & & Agar well diffusion method & 60 & 11 & [44] \\
\hline Mitragyna parvifolia & & Agar disc diffusion method & 75 & 17.50 & [46] \\
\hline Cinnamomum zeylanicum & & Agar well diffusion method & 10 & 18 & [56] \\
\hline Trigonella foenum-graecum & Citrobacter freundii & Agar well diffusion method & 62.0 & $11.0 \pm 1.0$ & [23] \\
\hline Trigonella foenum-graecum & $\begin{array}{l}\text { Enterobacter } \\
\text { agglomerans }\end{array}$ & Agar well diffusion method & 62.0 & $12.0 \pm 0.6$ & [23] \\
\hline Trigonella foenum-graecum & $\begin{array}{l}\text { Enterobacter } \\
\text { cloacae }\end{array}$ & Agar well diffusion method & 62.0 & $9.0 \pm 1.0$ & [23] \\
\hline Cinnamomum zeylanicum & Enterobacteria & Agar well diffusion method & 10 & 19 & [56] \\
\hline Moringa oleifera & $\begin{array}{l}\text { Enterococcus } \\
\text { faecalis }\end{array}$ & Resazurin microtiter assay & 10 & 250 & [13] \\
\hline Cissus vitiginea & Enterococcus sp. & Agar disc diffusion method & 75 & 20.3 & [26] \\
\hline Allium sativum & Escherichia coli & Agar well diffusion method & 75 & 13 & [1] \\
\hline Allium sativum & & Disc diffusion method & 10 & 19 & [4] \\
\hline Zingiber officinale & & Disc diffusion method & 10 & 18 & [4] \\
\hline Moringa oleifera & & Resazurin microtiter assay & 10 & 500 & [13] \\
\hline Clerodendrum inerme & & Agar well diffusion method & 0.30 & 0.80 & [16] \\
\hline Eryngium caucasicum & & Agar diffusion method & 60 & 23.3 & [17] \\
\hline \multicolumn{6}{|l|}{ Vaccinium sp. } \\
\hline Persea americana & & Broth dilution method & 0.4 & $117 \pm 27$ & [19] \\
\hline Trigonella foenum-graecum & & Disc diffusion method & 75 & $15.06 \pm 0.13$ & [22] \\
\hline Cissus vitiginea & & Agar well diffusion method & 62.0 & $14.0 \pm 0.6$ & [23] \\
\hline Citrus medica & & Kirby-Bauer disc diffusion assay & 75 & 22.2 & [26] \\
\hline Allium saralicum & & Disc diffusion method & 20 & 28 & [27] \\
\hline Allium eriophyllum & & Agar well diffusion method & 64 & $34.2 \pm 0.44$ & [31] \\
\hline Syzygium aromaticum & & Agar well diffusion method & 64 & $29.2 \pm 0.83$ & [32] \\
\hline Falcaria vulgaris & & Agar disc diffusion method & 16 & 6.0 & [37] \\
\hline Citrus limon & & Disc diffusion method & 64 & $22.2 \pm 0.44$ & [38] \\
\hline Piper retrofractum vahl & & $\begin{array}{l}\text { Agar well and disc diffusion } \\
\text { method }\end{array}$ & 25 & 4.5 & [41] \\
\hline Piper longum & & Kirby-Bauer disc diffusion assay & 0.2 & 2.0 & [43] \\
\hline Mitragyna parvifolia & & Agar well diffusion method & 60 & 12 & [44] \\
\hline Cissus arnotiana & & Agar disc diffusion method & 75 & 13.80 & [46] \\
\hline Prosopis cineraria & & Nutrient agar medium & 50 & $19.20 \pm 0.11$ & [47] \\
\hline Cinnamomum zeylanicum & & Disc diffusion method & 50 & $22.6 \pm 2.0$ & [55] \\
\hline \multirow[t]{2}{*}{ Artemesia haussknechti } & & Agar well diffusion method & 10 & 25 & [56] \\
\hline & & Agar disc diffusion method & 0.1 & $34 \pm 2.64$ & [60] \\
\hline Moringa oleifera & Klebsiella & Resazurin microtiter assay & 10 & 500 & [13] \\
\hline Trigonella foenum-graecum & pneumoniae & Agar well diffusion method & 62.0 & $16.0 \pm 1.0$ & [23] \\
\hline Citrus medica & & Disc diffusion method & 20 & 20 & [27] \\
\hline Prosopis cineraria & & Disc diffusion method & 50 & $22.7 \pm 1.0$ & [55] \\
\hline Clerodendrum inerme & Klebsiella sp. & Agar well diffusion method & 0.14 & 0.09 & [16] \\
\hline Persea Americana & & Agar well diffusion method & 75 & $20.16 \pm 0.13$ & [22] \\
\hline Cissus vitiginea & & Agar disc diffusion method & 75 & 18.5 & [26] \\
\hline Cissus arnotiana & & Nutrient agar medium & 50 & $15.20 \pm 0.12$ & [47] \\
\hline Zingiber officinale & $\begin{array}{l}\text { Listeria } \\
\text { monocytogenes }\end{array}$ & Kirby-Bauer disc diffusion assay & 20 & $55 \pm 1.25$ & [33] \\
\hline Punica granatum & Micrococcus luteus & Agar well diffusion method & 100 & $20.33 \pm 1.53$ & [24] \\
\hline Citrus medica & $\begin{array}{l}\text { Propionibacterium } \\
\text { acne }\end{array}$ & Disc diffusion method & 20 & 20 & [27] \\
\hline Cissus vitiginea & Proteus sp. & Agar disc diffusion method & 75 & 16.33 & [26] \\
\hline
\end{tabular}




\begin{tabular}{|c|c|c|c|c|c|}
\hline Plant extracts & Tested organisms & Media/Assay used & $\begin{array}{l}\text { Concentration } \\
(\mu \mathrm{g} / \mathrm{ml})\end{array}$ & $\begin{array}{l}\text { Diameter of zone of } \\
\text { inhibition }(\mu \mathrm{g} / \mathrm{ml}) \\
\text { /inhibition }(\%)\end{array}$ & References \\
\hline Prosopis cineraria & Proteus vulgaris & Disc diffusion method & 50 & $17.7 \pm 0.7$ & [55] \\
\hline Allium sativum & Pseudomonas & Disc diffusion method & 10 & 14 & {$[4]$} \\
\hline Zingiber officinale & aeruginosa & Disc diffusion method & 10 & 14 & {$[4]$} \\
\hline Trigonella foenum-graecum & & Agar well diffusion method & 62.0 & $14.0 \pm 0.6$ & [23] \\
\hline Punica granatum & & Agar well diffusion method & 100 & $18.67 \pm 1.53$ & [24] \\
\hline Allium saralicum & & Agar well diffusion method & 64 & $39.4 \pm 0.54$ & {$[31]$} \\
\hline Allium eriophyllum & & Agar well diffusion method & 64 & $30.6 \pm 0.89$ & {$[32]$} \\
\hline Piper longum & & Agar well diffusion method & 60 & 13 & {$[44]$} \\
\hline Prosopis cineraria & & Disc diffusion method & 50 & 18.1 & [55] \\
\hline Zingiber officinale & $\begin{array}{l}\text { Pseudomonas } \\
\text { fluorescens }\end{array}$ & Kirby-Bauer disc diffusion assay & 20 & $35 \pm 1.21$ & [33] \\
\hline Syzygium aromaticum & Pseudomonas sp. & Kirby-Bauer disc diffusion assay & 16 & 7 & [37] \\
\hline Cissus arnotiana & Rhizobium sp. & Nutrient agar medium & 50 & $16.07 \pm 0.25$ & {$[47]$} \\
\hline Persea americana & Rizhobacterium & Agar well diffusion method & 75 & $12.09 \pm 0.16$ & [22] \\
\hline Vaccinium sp. & $\begin{array}{l}\text { Saccharomyces } \\
\text { cerevisiae }\end{array}$ & Broth dilution method & 0.4 & 60 & [19] \\
\hline Punica granatum & Salmonella enterica & Agar well diffusion method & 100 & $18.67 \pm 1.53$ & {$[24]$} \\
\hline Citrus medica & Salmonella Typhi & Disc diffusion method & 20 & 22 & {$[27]$} \\
\hline Eryngium caucasicum & $\begin{array}{l}\text { Salmonella } \\
\text { typhimurium }\end{array}$ & Agar diffusion method & 100 & 23.1 & [17] \\
\hline Artemesia haussknechtii & Serratia marcescens & Agar disc diffusion method & 0.1 & $4 \pm 1.52$ & {$[60]$} \\
\hline Moringa oleifera & Staphylococcus & Resazurin microtiter assay & 10 & 500 & {$[13]$} \\
\hline Clerodendrum inerme & aureus & Agar well diffusion method & 0.10 & 0.95 & {$[16]$} \\
\hline Eryngium caucasicum & & Agar diffusion method & 60 & 21.33 & {$[17]$} \\
\hline Trigonella foenum-graecum & & Kirby-Bauer disc diffusion assay & 62.0 & $15 \pm 0.6$ & [23] \\
\hline Allium saralicum & & Agar well diffusion method & 64 & $35 \pm 1.22$ & {$[31]$} \\
\hline Allium eriophyllum & & Agar well diffusion method & 64 & $32 \pm 0.7$ & [32] \\
\hline Zingiber officinale & & Disc diffusion method & 20 & $40 \pm 0.87$ & {$[33]$} \\
\hline Falcaria vulgaris & & Disc diffusion method & 64 & $24.2 \pm 0.44$ & [38] \\
\hline $\begin{array}{l}\text { Citrus limon } \\
\text { Piper retrofractum }\end{array}$ & & $\begin{array}{l}\text { Agar well and disc diffusion } \\
\text { method }\end{array}$ & 25 & 2.2 & {$[41]$} \\
\hline \multirow[t]{2}{*}{ Piper longum } & & Kirby-Bauer disc diffusion assay & 0.2 & 1.4 & {$[43]$} \\
\hline & & Agar well diffusion method & 60 & 12 & {$[44]$} \\
\hline Prosopis cineraria & $\begin{array}{l}\text { Staphylococcus } \\
\text { epidermidis }\end{array}$ & Disc diffusion method & 50 & $23.0 \pm 1.0$ & {$[55]$} \\
\hline Allium saralicum & Streptococcus & Agar well diffusion method & 64 & $40.4 \pm 0.54$ & {$[31]$} \\
\hline Falcaria vulgaris & pneumonia & Disc diffusion method & 64 & $27.2 \pm 0.83$ & {$[38]$} \\
\hline Persea americana & Streptococcus sp. & Agar well diffusion method & 75 & $22.23 \pm 0.15$ & {$[22]$} \\
\hline Cissus arnotiana & & Nutrient agar medium & 50 & $20.59 \pm 0.12$ & {$[47]$} \\
\hline Ocimum sanctum & $\begin{array}{l}\text { Xanthomonas } \\
\text { axonopodis pv. citri }\end{array}$ & Potato dextrose agar media & 0.03 & $13.5 \pm 1.29$ & {$[30]$} \\
\hline Ocimum sanctum & $\begin{array}{l}\text { Xanthomonas } \\
\text { axonopodis pv. } \\
\text { Punicae }\end{array}$ & Potato dextrose agar media & 0.03 & 17.25 & {$[30]$} \\
\hline
\end{tabular}

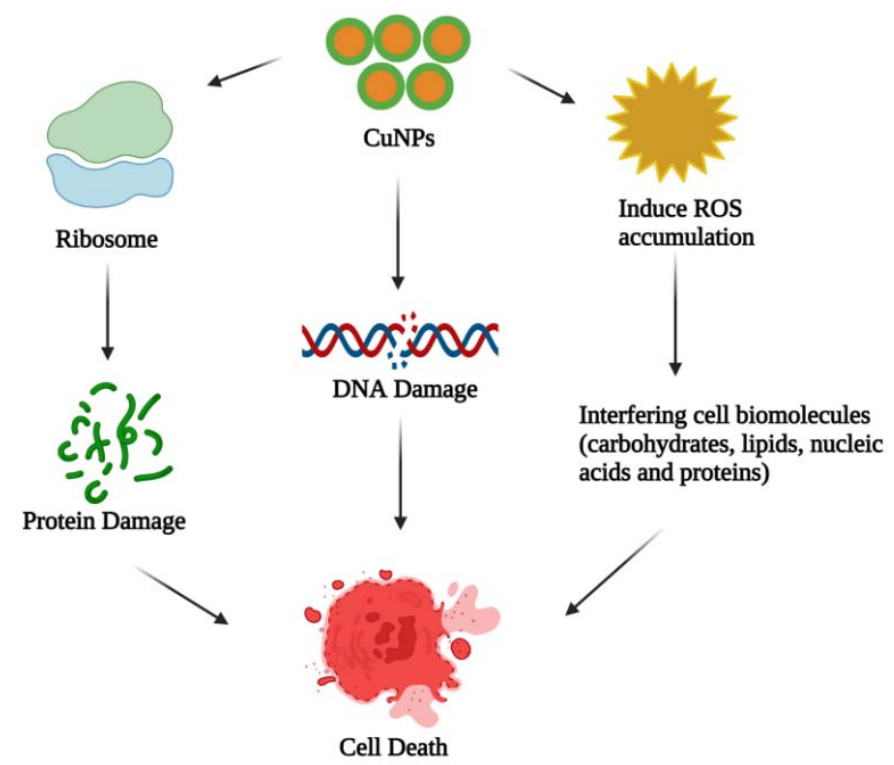

Fig. 9: Graphical representation for the hypothetical mechanism of antibacterial activity of copper nanoparticles 
Table 6: Antifungal activity of biosynthesized CuNPs

\begin{tabular}{|c|c|c|c|c|c|}
\hline Tested organisms & Plant extracts & Media/Assay used & $\begin{array}{l}\text { Concentration } \\
(\mu \mathrm{g} / \mathrm{ml})\end{array}$ & $\begin{array}{l}\text { Diameter of zone } \\
\text { of inhibition ( } \mathrm{mm}) \\
\text { /Inhibition (\%) }\end{array}$ & References \\
\hline Alternaria carthami & Ocimum sanctum & Potato dextrose agar media & 0.06 & $18.5 \pm 1.7$ & [30] \\
\hline Alternaria mali & Azadirachta indica & Modified Food Poisoning Technique & 0.05 & 80 & [29] \\
\hline \multirow[t]{6}{*}{ Aspergillus flavus } & Cissus quadrangularis & potato dextrose broth & $500 \mathrm{ppm}$ & 86 & [10] \\
\hline & Moringa oleifera & Resazurin Microtiter Assay & 15.6 & 125 & [13] \\
\hline & Clerodendrum inerme & Potato dextrose agar & 0.10 & $24 \pm 0.08$ & [16] \\
\hline & Persea americana & Agar well diffusion method & 75 & $9.5 \pm 0.2$ & [22] \\
\hline & Camellia sinensis & Broth dilution method & 10 & $11.3 \pm 1.2$ & [39] \\
\hline & Syzygium alternifolium & Disc diffusion assay & 40 & 8.2 & [52] \\
\hline Aspergillus fumigatus & Persea americana & Agar well diffusion method & 75 & 10 & [22] \\
\hline \multirow[t]{7}{*}{ Aspergillus niger } & Cissus quadrangularis & potato dextrose broth & 500 & 85 & [10] \\
\hline & Moringa oleifera & Resazurin Microtiter Assay & 7.8 & 125 & [13] \\
\hline & Clerodendrum inerme & Potato dextrose agar & 0.29 & $17 \pm 0.07$ & [16] \\
\hline & Ocimum sanctum & Potato dextrose agar media & 0.06 & $12.75 \pm 1.7$ & [30] \\
\hline & Zingiber officinale & Kirby-Bauer disc diffusion assay & 20 & $25 \pm 0.29$ & [33] \\
\hline & Syzygium alternifolium & Disc diffusion assay & 40 & 9.0 & [52] \\
\hline & Blumea balsamifera & Disc diffusion assay & 80 & $12 \pm 4$ & [57] \\
\hline $\begin{array}{l}\text { Aspergillus } \\
\text { parasiticus }\end{array}$ & Camellia sinensis & Broth dilution method & 10 & $18.4 \pm 1.6$ & [39] \\
\hline $\begin{array}{l}\text { Botryosphaeria } \\
\text { dothidea }\end{array}$ & Azadirachta indica & Modified Food Poisoning Technique & 0.25 & 85 & [29] \\
\hline \multirow{5}{*}{ Candida albicans } & Moringa oleifera & Resazurin Microtiter Assay & 31.2 & 62.5 & [13] \\
\hline & $\begin{array}{l}\text { Trigonella foenum- } \\
\text { graecum }\end{array}$ & Agar well diffusion method & 0.5 & 15.0 & [23] \\
\hline & Allium saralicum & Disc diffusion method & 60 & $39.6 \pm 0.89$ & [31] \\
\hline & Allium eriophyllum & Agar well diffusion method & 60 & $37.8 \pm 0.44$ & [32] \\
\hline & Falcaria vulgaris & Agar well diffusion method & 64 & $22.6 \pm 1.34$ & [38] \\
\hline \multirow[t]{4}{*}{ Candida glabrata } & Moringa oleifera & Resazurin Microtiter Assay & 62.5 & 31.2 & [13] \\
\hline & Allium saralicum & Disc diffusion method & 60 & $38.4 \pm 0.54$ & [31] \\
\hline & Allium eriophyllum & Agar well diffusion method & 60 & $39.6 \pm 1.14$ & [32] \\
\hline & Falcaria vulgaris & Agar well diffusion method & 64 & $24.6 \pm 1.34$ & [38] \\
\hline Candida & Allium saralicum & Disc diffusion method & 60 & $42.8 \pm 1.09$ & [31] \\
\hline \multirow[t]{2}{*}{ guilliermondii } & Allium eriophyllum & Agar well diffusion method & 60 & $39.6 \pm 1.14$ & [32] \\
\hline & Falcaria vulgaris & Agar well diffusion method & 64 & $26 \pm 1$ & [38] \\
\hline \multirow[t]{3}{*}{ Candida krusei } & Allium saralicum & Disc diffusion method & 60 & $39 \pm 1.22$ & [31] \\
\hline & Allium eriophyllum & Agar well diffusion method & 60 & $41.0 \pm 1.0$ & [32] \\
\hline & Falcaria vulgaris & Agar well diffusion method & 64 & $27.8 \pm 1.09$ & [38] \\
\hline $\begin{array}{l}\text { Colletotrichum } \\
\text { gloeosporioides }\end{array}$ & Ocimum sanctum & Potato dextrose agar media & 0.03 & $11.5 \pm 1.0$ & [30] \\
\hline $\begin{array}{l}\text { Colletotrichum } \\
\text { lindemuthianum }\end{array}$ & Ocimum sanctum & Potato dextrose agar media & 0.03 & $15.25 \pm 0.5$ & [30] \\
\hline Diplodia seriata & Azadirachta indica & Modified Food Poisoning Technique & 0.10 & 90 & [29] \\
\hline Fusarium culmorum & Citrus medica & Disc diffusion assay & 20 & 34 & [27] \\
\hline $\begin{array}{l}\text { Fusarium } \\
\text { graminearum }\end{array}$ & Citrus medica & Disc diffusion assay & 20 & 22 & [27] \\
\hline $\begin{array}{l}\text { Fusarium } \\
\text { moniliforme }\end{array}$ & Zingiber officinale & Kirby-Bauer disc diffusion assay & 20 & $20 \pm 0.93$ & [33] \\
\hline \multirow{4}{*}{ Fusarium oxysporum } & Curcuma longa & Agar diffusion method & 10 & 65 & [18] \\
\hline & Persea americana & Agar well diffusion method & 25 & $12.2 \pm 0.03$ & [22] \\
\hline & Citrus medica & Disc diffusion assay & 20 & 29 & [27] \\
\hline & Celastrus paniculatus & Food poison method & 0.24 & $76.29 \pm 1.52$ & [34] \\
\hline $\begin{array}{l}\text { Fusarium oxysporum } \\
\text { f. sp. carthami }\end{array}$ & Ocimum sanctum & Potato dextrose agar media & 0.06 & $14.75 \pm 1.25$ & [30] \\
\hline $\begin{array}{l}\text { Fusarium oxysporum } \\
\text { f. sp. cicero }\end{array}$ & Ocimum sanctum & Potato dextrose agar media & 0.03 & $13.5 \pm 1.25$ & {$[30]$} \\
\hline $\begin{array}{l}\text { Macrophomina } \\
\text { phaseolina }\end{array}$ & Ocimum sanctum & Potato dextrose agar media & 0.03 & $12.5 \pm 0.5$ & [30] \\
\hline Penicillium sp. & Syzygium aromaticum & Kirby-Bauer disc diffusion assay & 16 & 6 & [37] \\
\hline $\begin{array}{l}\text { Rhizoctonia } \\
\text { bataticola }\end{array}$ & Ocimum sanctum & Potato dextrose agar media & 0.03 & $10.5 \pm 0.5$ & [30] \\
\hline Rhizoctonia solani & Manilkara zapota & Potato dextrose agar media & $\begin{array}{l}50 \\
100 \\
200\end{array}$ & $\begin{array}{l}24.4 \\
56.6 \\
65.5\end{array}$ & [40] \\
\hline Rhizopus stolonifer & Ocimum sanctum & Potato dextrose agar media & 0.03 & $11.75 \pm 1.5$ & [30] \\
\hline Sclerotium oryzae & Manilkara zapota & Potato dextrose agar media & $\begin{array}{l}50 \\
100 \\
200\end{array}$ & $\begin{array}{l}61.1 \\
88.9 \\
100\end{array}$ & {$[40]$} \\
\hline
\end{tabular}


For the antibacterial mechanism, CuNPs intracellularly permeate the $\mathrm{Cu}^{2+}$ ions by interacting with the bacterial cell membrane. Many plant-derived CuNPs with antibacterial effects also have antioxidant characteristics. Likewise, CuNPs produced by $C$. vitiginea has antioxidant activity, which helps to limit the growth of bacteria that cause urinary tract infections. CuNPs from the extract Allium sativum and Allium eriophyllum leaf extract, on the other hand, have antibacterial properties, which could be owing to their antioxidant properties $[11,26,31,32]$. The hypothetical antibacterial mechanism of CuNPs is given in fig. 9.

\section{Antifungal activity}

Among the various species of fungi, Aspergillus and Fusarium species play a major role in influencing the yield of small grains. The plant extracts contain proteins found to protect the plants from fungal infection [92-95]. CuNPs generated from the various plant extracts showed better activity against fungal pathogens. CuNPs synthesized from Aspergillus flavus, Aspergillus niger, Candida sp., Fusarium sp. and Rhizoctonia solani exhibited better activity. Table 6 shows the susceptible fungal species, minimum inhibitory concentration and diameter zone of inhibition of fungal medicated biogenic CuNPs.

For the antifungal mechanism, CuNPs intracellularly permeates the $\mathrm{Cu}^{2+}$ ions by interacting with the fungal cell membrane. According to a recent study, the caused cell wall damage and accumulated reactive oxygen species (ROS) in Aspergillus flavus, demonstrating an antifungal activity. Furthermore, the CuNPs made from Allium sativum extract has antioxidant activity, which could contribute to the antifungal properties [11, 32]. The hypothetical antifungal mechanism of CuNPs is given in fig. 10.

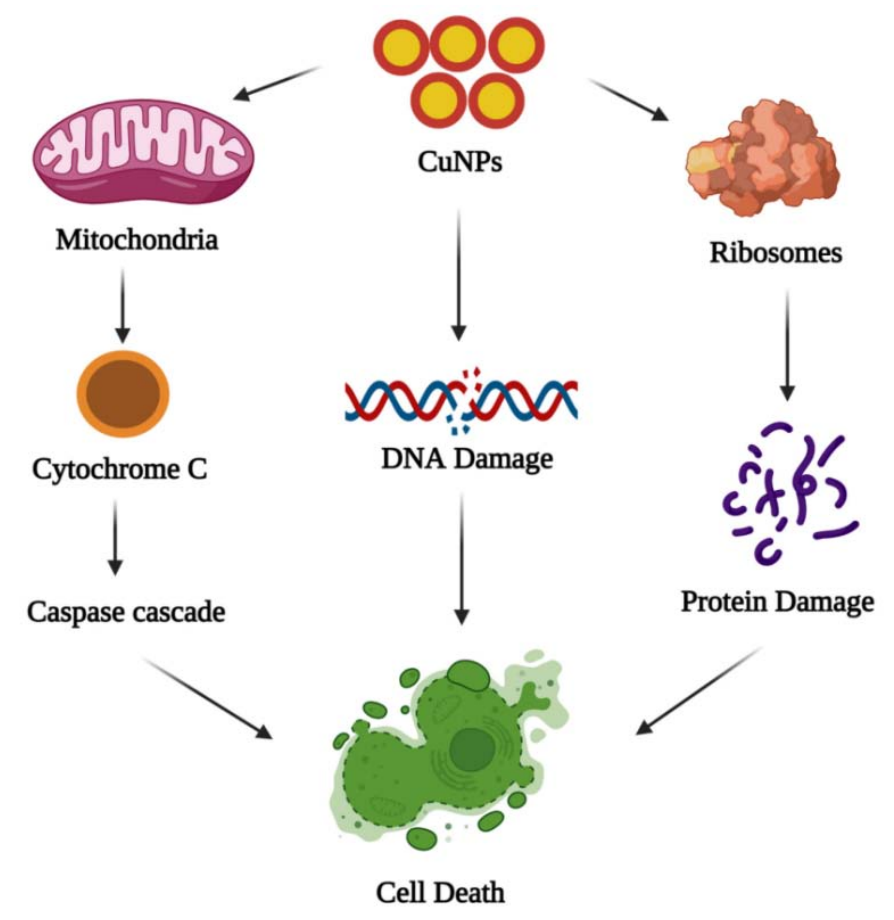

Fig. 10: Graphical representation of the hypothetical mechanism for the antifungal activity of copper nanoparticles

Table 7: Antioxidant activity of biosynthesized CuNPs

\begin{tabular}{|c|c|c|c|c|}
\hline Plant & Methods involved & Concentration $(\mu \mathrm{g} / \mathrm{ml})$ & $\begin{array}{l}\text { \% Scavenging } \\
\text { activity }\end{array}$ & References \\
\hline Moringa oleifera & $\begin{array}{l}\text { DPPH radical scavenging assay and } \\
\text { phosphomolybdate assay }\end{array}$ & 500 & 29.3 & [13] \\
\hline Azadirachta indica & ABTS, DPPH and $\mathrm{H}_{2} \mathrm{O}_{2}$ radical scavenging assay & 80 & 38 & [14] \\
\hline Hibiscus rosa-sinensis & ABTS, DPPH and $\mathrm{H}_{2} \mathrm{O}_{2}$ radical scavenging assay & 80 & 21.06 & [14] \\
\hline Murraya koenigii & ABTS, DPPH and $\mathrm{H}_{2} \mathrm{O}_{2}$ radical scavenging assay & 80 & 25.89 & [14] \\
\hline Tamarindus indica & ABTS, DPPH and $\mathrm{H}_{2} \mathrm{O}_{2}$ radical scavenging assay & 80 & 34.82 & [14] \\
\hline Eclipta prostrata & DPPH radical scavenging assay & 500 & 53 & [15] \\
\hline Abutilon indicum & DPPH radical scavenging assay & 60 & $90 \pm 0.23$ & [16] \\
\hline Clerodendrum inerme & DPPH radical scavenging assay & 60 & $83 \pm 0.23$ & [16] \\
\hline Clerodendrum infortunatum & DPPH radical scavenging assay & 60 & $78 \pm 0.25$ & [16] \\
\hline Eryngium caucasicum trautv & DPPH radical scavenging assay & 100 & 58.98 & [17] \\
\hline Persea americana & DPPH radical scavenging assay & 80 & 22 & [22] \\
\hline Trigonella foenum-graecum & DPPH radical scavenging assay & 20 kGy (radiation source) & 43 & [23] \\
\hline Cissus vitiginea & DPPH radical scavenging assay & 40 & 21 & [26] \\
\hline Allium saralicum & DPPH radical scavenging assay & 250 & 228 & [31] \\
\hline Allium eriophyllum & DPPH radical scavenging assay & 250 & 206 & [32] \\
\hline Zingiber officinale & DPPH and $\mathrm{H}_{2} \mathrm{O}_{2}$ radical scavenging assay & 20 & $75 \pm 0.87$ & [33] \\
\hline Falcaria vulgaris & DPPH radical scavenging assay & 125 & 109 & [38] \\
\hline Cissus arnotiana & DPPH radical scavenging assay & 40 & $21 \pm 2$ & [47] \\
\hline Olea europea & DPPH radical scavenging assay & 400 & 45 & [59] \\
\hline Artemesia haussknechtii & DPPH radical scavenging assay & 500 & 74.45 & [60] \\
\hline Magnolia champaca & ABTS and DPPH radical scavenging assay & 500 & 76.30 & [70] \\
\hline
\end{tabular}




\section{Antioxidant activity}

Anti-oxidant activity is a capability of a biological compound to inhibit lipid oxidation reaction and to maintain the function and structure of cells by destroying the free radicals. Flavanoids, particularly naringin, naringenin, hesperidin, quercetin and rutin, have antioxidant activity by inhibiting oxidant enzymes in the body, enhancing antioxidant enzyme activity, scavenging ROS directly, anti-lipid oxidation and decreasing the quality of peroxide formation [96-97]. CuNPs generated from the various plant extracts showed a greater scavenging activity. CuNPs generated from the leaves extract Abutilon indicum, Clerodendrum infortunatum and Clerodendrum inerme showed better scavenging activity [16]. The percentage of scavenging activity prior to its plant extract concentration is given in table 7 .

\section{Anticancer activity}

Apoptosis induction and inhibition of tumor cell proliferation are the approaches engaged in the treatment of cancer. Anti-cancer agents exhibit high toxicity to the tumor cell and also to the normal cells of the body where cancer developed $[98,99]$. CuNPs obtained from the various plant extracts exhibited anticancer activity, particularly in breast, cervical, colon, epithelial, liver, lung and skin cancers. The
CuNPs obtained from the species like Tilia cordata [36], Manilkara zapota [40] and Prosopis cineraria [55] exhibited better cytotoxicity against MCF-7 (breast) cell line. CuNPs from the leaves extract of Olea europea [59] showed inhibition against AMJ-13 (breast) cancer cell line Against MDA-MB-231, Abutilon indicum, Clerodendrum inerme, Clerodendrum infortunatum [16] and Syzygium alternifolium [52] showed the activity. Zingiber officinale [4], Azadirachta indica, Hibiscus rosa-sinensis, Murraya koenigii and Tamarindus indica [14] showed anticancer activity against HeLa (cervical) cell line. Tilia cordata [36] exhibited cytotoxicity against Caco-2 (colon) cell line. The growth inhibition of the Hep-2 (epithelioma) cell line was observed by the CuNPs prepared using the leaves extract of Azadirachta indica, Hibiscus rosa-sinensis, Murraya koenigii and Tamarindus indica [14]. The CuNPs from the green extract of Allium saralicum [31], Allium eriophyllum [32] and Falcaria vulgaris [38] inhibited the growth of the HUVEC (umbilical vein) cell line. Against the HepG2 (liver) cell line, the CuNPs prepared from the extracts of Allium sativum, Zingiber officinale [4], Eclipta prostrate [15] and Tilia cordata [36] exhibited better inhibition. Azadirachta indica, Hibiscus rosa-sinensis, Murraya koenigii, Tamarindus indica [14] and Quisqualis indica [50] exhibited better anticancer activity against A549 (lung) and B16F10 (melanoma) cell lines, respectively. The activity against various cell lines is given in table 8 .

Table 8: Anticancer activity of biosynthesised CuNPs

\begin{tabular}{|c|c|c|c|c|c|}
\hline Types of cell & Cell lines & Plant extracts & Assay/Method involved & Ic $c_{50}$ value $(\mu \mathrm{g} / \mathrm{ml})$ & Reference \\
\hline \multirow[t]{6}{*}{ Breast cancer } & AMJ-13 & Olea europea & MTT assay & 1.47 & [59] \\
\hline & MCF-7 & Tilia cordata & MTT assay & 12.21 & [36] \\
\hline & MDA-MB-231 & Manilkara zapota & MTT assay & 53.89 & [40] \\
\hline & & Prosopis cineraria & MTT assay & 65.27 & [55] \\
\hline & & Clerodendrum inerme & MTT assay & $85 \pm 0.05$ & [16] \\
\hline & & Syzygium alternifolium & MTT assay & 50 & [52] \\
\hline \multirow[t]{2}{*}{ Cervical cancer } & HeLa & Zingiber officinale & MTT assay & $<80$ & [4] \\
\hline & & Azadirachta indica & MTT assay & $20.32 \pm 1.16$ & [14] \\
\hline Colon cancer & Caco-2 & Tilia cordata & MTT assay & 11.21 & [36] \\
\hline Epithelioma & Нер-2 & Azadirachta indica & MTT assay & $21.66 \pm 1.22$ & [14] \\
\hline \multirow[t]{3}{*}{ Endothelial cell } & HUVEC & Allium saralicum & MTT assay & 85 & [31] \\
\hline & & Allium eriophyllum & MTT assay & 95 & [32] \\
\hline & & Falcaria vulgaris & MTT assay & 85 & [38] \\
\hline \multirow[t]{3}{*}{ Liver cancer } & HepG2 & Zingiber officinale & MTT assay & $<80$ & [4] \\
\hline & & Eclipta prostrate & MTT assay & 500 & [15] \\
\hline & & Tilia cordata & MTT assay & 19.88 & [36] \\
\hline Lung cancer & A549 & Azadirachta indica & MTT assay & $18.11 \pm 0.93$ & [14] \\
\hline Melanoma & $\mathrm{B} 16 \mathrm{~F} 10$ & Quisqualis indica & MTT assay & 102 & [50] \\
\hline
\end{tabular}

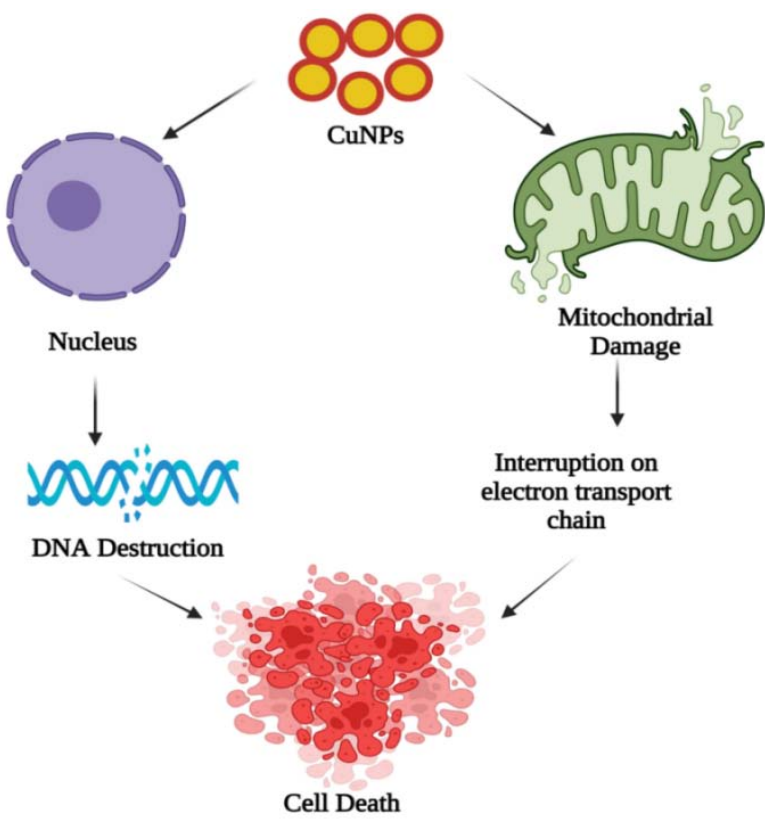

Fig. 11: Graphical representation of the hypothetical mechanism for the anticancer activity of copper nanoparticles 
Most of the plant extracts induced apoptosis by the generation of ROS and nitrogen oxide. The uptake of the synthesized CuNPs regulated the nitrogen oxide level in various cancer cell lines. Some of the extracts caused G2/M cell cycle arrest and increased p53 expression, as well as inhibiting histone deacetylase, which removes the acetyl group on histones to form a non-transcriptional compact chromatin structure. The Bak/Bax expression, BCl-2, caspase- 9 and caspase-7 were up regulated on treating with CuNPs. Some of the extracts decreased the level of various enzymes and increased tumor suppressing genes [11]. The hypothetical mechanism of CuNPs in the anticancer activity is given in fig. 11 .

\section{Antidiabetic activity}

$\alpha$-amylase and $\alpha$-glucosidase are the most favourable candidates for the prevention and treatment of T2DM. The two most significant methods for diabetes control are inhibition of $\alpha$-amylase and $\alpha$ glucosidase and scavenging of free radicals. CuNPs obtained from the leaves extract of Gnidia glauca and Plumbago zeylanica against porcine pancreatic amylase inhibition assay exhibited the most promising inhibition as that of standard acarbose. From the $\alpha$ glucosidase inhibition assay, the synthesised CuNPs showed the highest $\alpha$-glucosidase inhibition as that of standard acarbose. The circular dichroism analysis was also performed and it revealed the nature of the interaction of CuNPs with Porcine pancreatic $\alpha$ amylase and $\alpha$-glucosidase [51].

\section{Antinociceptive activity}

Pain is a sensory and defensive system that alerts the living organism to the dangers in its environment and allows it to respond appropriately. The antinociceptive effect of the synthesized CuNPs from the fruit extract of Capparis spinosa was evaluated by tail-flick method, hot plate method and rotarod method using mice model. The antinociceptive effect was achieved in combination with morphine. As a dose-dependent response, CuNPs at the concentration of 25, 50 and $75 \mathrm{mg} / \mathrm{kg}$ had potent antinociceptive activity [48].

\section{Wound healing activity}

Physical damage, water loss and harmful chemical invasion are all protected by the skin. A wound is when the integrity of the skin's normal anatomical structure is compromised. The term "healing" refers to the return of normal anatomical structure and function. The phases of haemostasis, inflammation, proliferation, and remodelling, which involve cutaneous cell-cell and cell-matrix interactions, make up wound healing [32]. The CuNPs obtained from the extracts of Allium saralicum [31], Allium eriophyllum [32] and Falcaria vulgaris [38] exhibited notable cutaneous wound healing activity. The CuNPs/CuNPs ointment obtained from the above extracts increased the concentration of hydroxyproline, hexosamine, hexuronic acid and fibrocyte/fibroblast ratio significantly.

\section{LIMITATIONS}

There is insufficient data to compare the various precursors and their effects on the green synthesis of CuNPs. Several investigations indicate that more research is needed to establish the effect of precursors on the size and form of NPs generated from plants. Increased quantities of plant extract have been used to accelerate the reduction of copper ions in solution, which increases the rate of synthesis of CuNPs. Due to the addition of an excess amount of plant extracts, the morphology of the particles will be changed. During long-term storage, NPs can aggregate, shrink, or expand and they also have a shelf life that impacts their total potential. The size of NPs depends upon the reaction time and temperature. i.e., a higher temperature is required to synthesize the smaller NPs [100-103].

\section{FUTURE DIRECTIONS}

NPs have recently been used as nanomedicines that can be used as delivery agents by encapsulating or attaching therapeutic pharmaceuticals and more effectively delivering them to the targeted tissues or cells. Due to their advantages like costeffectiveness, quick, and non-hazardous nature, it can be used in commercial productions and used to treat various diseases and disorders using targeted drug delivery concept. They are made at tiny sizes to allow unrestricted mobility in the human body while destroying cancer cells and also by means of transdermal delivery, the treatment of diabetes, wounds, burns, etc. will be achieved.

\section{CONCLUSION}

Using traditional physical and chemical processes necessitated the use of hazardous substances at a significant expense. The synthesis of nanoparticles using a biological approach is an eco-friendly, nontoxic, cost-effective and rapid approach. This review has focussed on the greater benefit of the biological method of synthesizing CuNPs. It gives the summarized data of the plants and micro-organisms used in the preparation of CuNPs, along with its characterization techniques. Copper nanoparticles synthesized by biological method express anti-oxidant, anti-cancer, anti-bacterial, anti-fungal, antidiabetic, antinociceptive and cutaneous wound healing activities. The limitations like the effect of the precursors, extracts along with time and temperature, are also discussed.

\section{ACKNOWLEDGEMENT}

We thank the Management and Dr. G. Murugananthan, Principal of our college for giving constant support and encouragement for writing this review.

\section{FUNDING}

Nil

\section{AUTHORS CONTRIBUTIONS}

All the authors have contributed equally.

\section{CONFLICTS OF INTERESTS}

Declare none

\section{REFERENCES}

1. Joseph AT, Prakash P, Narvi SS. Phytofabrication and characterization of copper nanoparticles using Allium sativum and its antibacterial activity. Int J Sci Eng Technol. 2016;4:463-72.

2. Gupta M. Biosynthesized silver nanoparticles using Catharanthus roseus and their antibacterial efficacy in synergy with antibiotics: a future advancement in nanomedicine. Asian J Pharm Clin Res. 2021;14(2):116-24. doi: 10.22159/ajpcr.2021.v14i2.39856.

3. Shende S, Bhagat R, Raut R, Rai M, Gade A. Myco-fabrication of copper nanoparticles and its effect on crop pathogenic fungi. IEEE Trans Nanobioscience. 2021;20(2):146-53. doi: 10.1109/TNB.2021.3056100, PMID 33523815.

4. Yaqub A, Malkani N, Shabbir A, Ditta SA, Tanvir F, Ali S, Naz M, Kazmi SAR, Ullah R. Novel biosynthesis of copper nanoparticles using zingiber and allium sp. with synergic effect of doxycycline for anticancer and bactericidal activity. Curr Microbiol. 2020;77(9):2287-99. doi: 10.1007/s00284-020-02058-4, PMID 32535649 .

5. Wang Z, Fang H, Wang S. Benzoic acid interactions affect aquatic properties and toxicity of copper oxide nanoparticles. Bull Environ Contam Toxicol. 2016;97(2):159-65. doi: 10.1007/s00128-016-1804-9, PMID 27098254.

6. Akturk A, Guler FK, Taygun ME, Goller G, Küçükbayrak S. Synthesis and antifungal activity of soluble starch and sodium alginate capped copper nanoparticles. Mater Res Express. 1250g3;6(12):6(12). doi: 10.1088/2053-1591/ab677e.

7. Sharma AK, Kumar A, Taneja G, Nagaich U, Deep A, Datusalia AK, Rajput SK. Combined and individual strategy of exercise generated preconditioning and low dose copper nanoparticles serve as a superlative approach to ameliorate ISO-induced myocardial infarction in rats. Pharmacol Rep. 2018;70(4):78995. doi: 10.1016/j.pharep.2018.02.023, PMID 29957339.

8. Kruk T, Szczepanowicz K, Stefanska J, Socha RP, Warszynski P. Synthesis and antimicrobial activity of monodisperse copper nanoparticles. Colloids Surf B Biointerfaces. 2015;128:17-22. doi: 10.1016/j.colsurfb.2015.02.009. PMID 25723345.

9. Mudiar R, Kelkar Mane V. Original research article (Experimental): targeting fungal menace through copper nanoparticles and Tamrajal. J Ayurveda Integr Med. 2020;11(3):316-21. doi: 10.1016/j.jaim.2018.02.134, PMID 30594354 . 
10. Devipriya D, Roopan SM. Cissus quadrangularis mediated ecofriendly synthesis of copper oxide nanoparticles and its antifungal studies against Aspergillus niger, Aspergillus flavus. Mater Sci Eng C Mater Biol Appl. 2017;80:38-44. doi: 10.1016/j.msec.2017.05.130, PMID 28866178.

11. Letchumanan D, Sok SPM, Ibrahim S, Nagoor NH, Arshad NM. Plant-based biosynthesis of copper/copper oxide nanoparticles: an update on their applications in biomedicine, mechanisms, and toxicity. Biomolecules. 2021;11(4):564. doi: 10.3390/biom11040564, PMID 33921379.

12. Ammar HA, Rabie GH, Mohamed E. Novel fabrication of gelatinencapsulated copper nanoparticles using Aspergillus versicolor and their application in controlling of rotting plant pathogens. Bioprocess Biosyst Eng. 2019;42(12):1947-61. doi: 10.1007/s00449-019-02188-5, PMID 31435736.

13. Das PE, Abu-Yousef IA, Majdalawieh AF, Narasimhan S, Poltronieri P. Green synthesis of encapsulated copper nanoparticles using a hydroalcoholic extract of Moringa oleifera leaves and assessment of their antioxidant and antimicrobial activities. Molecules. 2020;25(3):555. doi: 10.3390/molecules25030555, PMID 32012912.

14. Rehana D, Mahendiran D, Kumar RS, Rahiman AK. Evaluation of antioxidant and anticancer activity of copper oxide nanoparticles synthesized using medicinally important plant extracts. Biomed Pharmacother. 2017;89:1067-77. doi: 10.1016/j.biopha.2017.02.101, PMID 28292015.

15. Chung IM, Abdul Rahuman A, Marimuthu S, Kirthi AV, Anbarasan K, Padmini P, Rajakumar G. Green synthesis of copper nanoparticles using Eclipta prostrata leaves extract and their antioxidant and cytotoxic activities. Exp Ther Med. 2017;14(1):18-24. doi: 10.3892/etm.2017.4466, PMID 28672888.

16. Khan SA, Noreen F, Kanwal S, Iqbal A, Hussain G. Green synthesis of $\mathrm{ZnO}$ and $\mathrm{Cu}$-doped $\mathrm{ZnO}$ nanoparticles from leaf extracts of Abutilon indicum, Clerodendrum infortunatum, Clerodendrum inerme and investigation of their biological and photocatalytic activities. Mater Sci Eng C Mater Biol Appl. 2018;82:46-59. doi: 10.1016/j.msec.2017.08.071, PMID 29025674.

17. Hasheminya SM, Dehghannya J. Green synthesis and characterization of copper nanoparticles using Eryngium caucasicum Trautv aqueous extracts and its antioxidant and antimicrobial properties. Part Sci Technol. 2020;38(8):101926. doi: 10.1080/02726351.2019.1658664.

18. Sathiyabama M, Indhumathi M, Amutha T. Preparation and characterization of curcumin functionalized copper nanoparticles and their application enhances disease resistance in chickpea against wilt pathogen. Biocatal Agric Biotechnol. 2020;29. doi: 10.1016/j.bcab.2020.101823, PMID 101823.

19. Benassai E, Del Bubba M, Ancillotti C, Colzi I, Gonnelli C, Calisi N, Salvatici MC, Casalone E, Ristori S. Green and cost-effective synthesis of copper nanoparticles by extracts of non-edible and waste plant materials from Vaccinium species: characterization and antimicrobial activity. Mater Sci Eng C Mater Biol Appl. 2021;119:111453. doi: 10.1016/j.msec.2020.111453.

20. Mosa KA, El-Naggar M, Ramamoorthy K, Alawadhi H, Elnaggar A, Wartanian S, Ibrahim E, Hani H. Copper nanoparticles induced genotoxicty, oxidative stress, and changes in superoxide dismutase (SOD) gene expression in cucumber (Cucumis sativus) plants. Front Plant Sci. 2018;9:872. doi: 10.3389/fpls.2018.00872, PMID 30061904.

21. Weisany W, Samadi S, Amini J, Hossaini S, Yousefi S, Maggi F. Enhancement of the antifungal activity of thyme and dill essential oils against Colletotrichum nymphaeae by nanoencapsulation with copper NPs. Ind Crops Prod. 2019;132:21325. doi: 10.1016/j.indcrop.2019.02.031.

22. Rajeshkumar S, Rinitha G. Nanostructural characterization of antimicrobial and antioxidant copper nanoparticles synthesized using novel Persea americana seeds. OpenNano. 2018;3:18-27. doi: 10.1016/j.onano.2018.03.001.

23. El-Batal AI, Al-Hazmi NE, Mosallam FM, El-Sayyad GS. Biogenic synthesis of copper nanoparticles by natural polysaccharides and Pleurotus ostreatus fermented fenugreek using gamma rays with antioxidant and antimicrobial potential towards some wound pathogens. Microb Pathog. 2018;118:159-69. doi: 10.1016/j.micpath.2018.03.013, PMID 29530808.

24. Kaur P, Thakur R, Chaudhury A. Biogenesis of copper nanoparticles using peel extract of Punica granatum and their antimicrobial activity against opportunistic pathogens. Green Chem Lett Rev. 2016;9(1):33-8. doi: 10.1080/17518253.2016.1141238.

25. Paril P, Baar J, Cermak P, Rademacher P, Prucek R, Sivera M, Panacek A. Antifungal effects of copper and silver nanoparticles against white and brown-rot fungi. J Mater Sci. 2017;52(5):2720-9. doi: 10.1007/s10853-016-0565-5.

26. Wu S, Rajeshkumar S, Madasamy M, Mahendran V. Green synthesis of copper nanoparticles using Cissus vitiginea and its antioxidant and antibacterial activity against urinary tract infection pathogens. Artif Cells Nanomed Biotechnol. 2020;48(1):1153-8. doi: 10.1080/21691401.2020.1817053, PMID 32924614.

27. Shende S, Ingle AP, Gade A, Rai M. Green synthesis of copper nanoparticles by Citrus medica Linn. (Idilimbu) juice and its antimicrobial activity. World J Microbiol Biotechnol. 2015;31(6):865-73. doi: 10.1007/s11274-015-1840-3, PMID 25761857.

28. Shende S, Gaikwad N, Bansod S. Synthesis and evaluation of antimicrobial potential of copper nanoparticle against agriculturally important phytopathogens. Synthesis. 2016;1(4):41-7.

29. Ahmad H, Venugopal K, Bhat AH, Kavitha K, Ramanan A, Rajagopal K, Srinivasan R, Manikandan E. Enhanced biosynthesis synthesis of copper oxide nanoparticles (CuONPs) for their antifungal activity toxicity against major phytopathogens of apple orchards. Pharm Res. 2020;37(12):246. doi: 10.1007/s11095-020-02966-x, PMID 33215292.

30. Shende S, Gaikwad N, Bansod S. Synthesis and evaluation of antimicrobial potential of copper nanoparticle against agriculturally important phytopathogens. Synthesis. 2016;1(4):41-7.

31. Tahvilian R, Zangeneh MM, Falahi H, Sadrjavadi K, Jalalvand AR, Zangeneh A. Green synthesis and chemical characterization of copper nanoparticles using Allium saralicum leaves and assessment of their cytotoxicity, antioxidant, antimicrobial, and cutaneous wound healing properties. Appl Organometal Chem. 2019;33(12):e5234. doi: 10.1002/aoc.5234.

32. Zhao H, Su H, Ahmeda A, Sun Y, Li Z, Zangeneh MM, Nowrozi M, Zangeneh A, Moradi R. Biosynthesis of copper nanoparticles using Allium eriophyllum Boiss leaf aqueous extract; characterization and analysis of their antimicrobial and cutaneous wound-healing potentials. Appl Organometal Chem. 2020:e5587. doi: 10.1002/aoc.5587.

33. Pandit R, Gaikwad S, Rai M. Biogenic fabrication of CuNPs, $\mathrm{Cu}$ bioconjugates and in vitro assessment of antimicrobial and antioxidant activity. IET Nanobiotechnol. 2017;11(5):568-75. doi: 10.1049/iet-nbt.2016.0165, PMID 28745291.

34. Mali SC, Dhaka A, Githala CK, Trivedi R. Green synthesis of copper nanoparticles using Celastrus paniculatus willd. leaf extract and their photocatalytic and antifungal properties. Biotechnol Rep (Amst). 2020;27:e00518. doi: 10.1016/j.btre.2020.e00518. PMID 32923378.

35. Zhang Z, Ke M, Qu Q, Peijnenburg WJGM, Lu T, Zhang Q, Ye Y, Xu $\mathrm{P}, \mathrm{Du} \mathrm{B}$, Sun L, Qian H. Impact of copper nanoparticles and ionic copper exposure on wheat (Triticum aestivum L.) root morphology and antioxidant response. Environ Pollut. 2018;239:689-97. doi: 10.1016/j.envpol.2018.04.066, PMID 29715688.

36. Hassanien R, Husein DZ, Al-Hakkani MF. Biosynthesis of copper nanoparticles using aqueous Tilia extract: antimicrobial and anticancer activities. Heliyon. 2018;4(12):e01077. doi: 10.1016/j.heliyon.2018.e01077, PMID 30603710.

37. Rajesh KM, Ajitha B, Reddy YAK, Suneetha Y, Reddy PS. Assisted green synthesis of copper nanoparticles using Syzygium aromaticum bud extract: physical, optical and antimicrobial properties. Optik. 2018;154:593-600. doi: 10.1016/j.ijleo.2017.10.074. ijleo.2017.10.074.

38. Zangeneh MM, Ghaneialvar H, Akbaribazm M, Ghanimatdan M, Abbasi N, Goorani S, Pirabbasi E, Zangeneh A. Novel synthesis 
of Falcaria vulgaris leaf extract conjugated copper nanoparticles with potent cytotoxicity, antioxidant, antifungal, antibacterial, and cutaneous wound healing activities under in vitro and in vivo condition. J Photochem Photobiol B. 2019;197:111556. doi: 10.1016/j.jphotobiol.2019.111556.

39. Asghar MA, Zahir E, Shahid SM, Khan MN, Asghar MA, Iqbal J, Walker G. Iron, copper and silver nanoparticles: green synthesis using green and black tea leaves extracts and evaluation of antibacterial, antifungal and aflatoxin b1 adsorption activity. LWT. 2018;90:98-107. doi: 10.1016/j.lwt.2017.12.009.

40. Kiriyanthan RM, Sharmili SA, Balaji R, Jayashree S, Mahboob S, Al-Ghanim KA, Al-Misned F, Ahmed Z, Govindarajan M, Vaseeharan B. Photocatalytic, antiproliferative and antimicrobial properties of copper nanoparticles synthesized using Manilkara zapota leaf extract: a photodynamic approach. Photodiagn Photodyn Ther. 2020;32:102058. doi: 10.1016/j.pdpdt.2020.102058.

41. Amer MW, Awwad AM. Green synthesis of copper nanoparticles by Citrus limon fruits extract, characterization and antibacterial activity. Chem Int. 2021;7(1):1-8. doi: 10.5281/zenodo.4017993.

42. Khani R, Roostaei B, Bagherzade G, Moudi M. Green synthesis of copper nanoparticles by fruit extract of Ziziphus spina-christi (L.) willd.: application for adsorption of triphenylmethane dye and antibacterial assay. J Mol Liq. 2018;255:541-9. doi: 10.1016/j.molliq.2018.02.010. molliq.2018.02.010.

43. Amaliyah S, Pangesti DP, Masruri M, Sabarudin A, Sumitro SB. Green synthesis and characterization of copper nanoparticles using Piper retrofractum Vahl extract as bioreductor and capping agent. Heliyon. 2020;6(8):e04636. doi: 10.1016/j.heliyon.2020.e04636, PMID 32793839.

44. Shah R, Pathan A, Vaghela H, Ameta SC, Parmar K. Green synthesis and characterization of copper nanoparticles using mixture (Zingiber officinale, Piper nigrum and Piper longum) extract and its antimicrobial activity. Chem Sci Trans. 2019;8(1):63-9. doi: 10.7598/cst2019.1517.

45. Aher HR, Han SH, Vikhe A, Kuchekar S. Green synthesis of copper nanoparticles using Syzygium cumin, leaf extract, characterization and antimicrobial activity. Chem Sci Trans. 2019;8(1):1-6. doi: 10.7598/cst2019.1552.

46. Kotval SC, John T, Parmar KA. Green synthesis of copper nanoparticles using Mitragyna parvifolia plant bark extract and its antimicrobial study. JNST. 2018;4(4):456-60. doi: 10.30799/jnst.133.18040415.

47. Rajeshkumar S, Menon S, Venkat Kumar S, Tambuwala MM, Bakshi HA, Mehta M, Satija S, Gupta G, Chellappan DK, Thangavelu L, Dua K. Antibacterial and antioxidant potential of biosynthesized copper nanoparticles mediated through Cissus arnotiana plant extract. J Photochem Photobiol B. 2019;197:111531. doi: 10.1016/j.jphotobiol.2019.111531.

48. Mahmoudvand H, Khaksarian M, Ebrahimi K, Shiravand S, Jahanbakhsh S, Niazi M, Nadri S. Antinociceptive effects of green synthesized copper nanoparticles alone or in combination with morphine. Ann Med Surg (Lond). 2020;51:31-6. doi: 10.1016/j.amsu.2019.12.006. PMID 32042414.

49. Prabhu YT, Venkateswara Rao K, Sesha Sai V, Pavani T. A facile biosynthesis of copper nanoparticles: A micro-structural and antibacterial activity investigation. J Saudi Chem Soc. 2017;21(2):180-5. doi: 10.1016/j.jscs.2015.04.002.

50. Mukhopadhyay R, Kazi J, Debnath MC. Synthesis and characterization of copper nanoparticles stabilized with Quisqualis indica extract: evaluation of its cytotoxicity and apoptosis in B16F10 melanoma cells. Biomed Pharmacother. 2018;97:1373-85. doi: 10.1016/j.biopha.2017.10.167, PMID 29156527.

51. Jamdade DA, Rajpali D, Joshi KA, Kitture R, Kulkarni AS, Shinde VS, Bellare J, Babiya KR, Ghosh S. Gnidia glauca- and plumbago zeylanica-mediated synthesis of novel copper nanoparticles as promising antidiabetic agents. Adv Pharmacol Sci. 2019;2019:9080279. doi: 10.1155/2019/9080279.

52. Yugandhar P, Vasavi T, Uma Maheswari Devi PU, Savithramma N. Bioinspired green synthesis of copper oxide nanoparticles from Syzygium alternifolium (Wt.) Walp: characterization and evaluation of its synergistic antimicrobial and anticancer activity. Appl Nanosci. 2017;7(7):417-27. doi: 10.1007/s13204-017-0584-9.

53. Paul JJ, Sakunthala M. Green synthesis of copper nanoparticles using Ctenolepis garcini (Burm. f) clarke CB. Int J Nanobiotechnol. 2017;3(2):1-6.

54. Paragas DS, Cruz KD, Fiegalan ER. Green synthesized copper nanoparticles from Blumea balsamifera linn. leaves and its biocidal activities against Bactrocera dorsalis (Hendel). Malays J Anal Sci. 2020;24(3):436-48.

55. Jinu U, Gomathi M, Saiqa I, Geetha N, Benelli G, Venkatachalam P. Green engineered biomolecule-capped silver and copper nanohybrids using Prosopis cineraria leaf extract: enhanced antibacterial activity against microbial pathogens of public health relevance and cytotoxicity on human breast cancer cells (MCF-7). Microb Pathog. 2017;105:86-95. doi: 10.1016/j.micpath.2017.02.019, PMID 28214590. micpath.2017.02.019.

56. Kothari R. Copper nanoparticles synthesized from Cinnamomum zeylanicum and its antibacterial activity. Am J Nanosci Nanotechnol. 2018;6(1):1-7.

57. Shammout M, Awwad A. A novel route for the synthesis of copper oxide nanoparticles using Bougainvillea plant flowers extract and antifungal activity evaluation. Chem Int. 2021;7(1):71-8.

58. Ituen E, Ekemini E, Yuanhua L, Li R, Singh A. Mitigation of microbial biodeterioration and acid corrosion of pipework steel using Citrus reticulata peels extract mediated copper nanoparticles composite. Int Biodeterior Biodegrad. 2020;149. doi: 10.1016/j.ibiod.2020.104935, PMID 104935.

59. Sulaiman GM, Tawfeeq AT, Jaaffer MD. Biogenic synthesis of copper oxide nanoparticles using Olea europaea leaf extract and evaluation of their toxicity activities: an in vivo and in vitro study. Biotechnol Prog. 2018;34(1):218-30. doi: 10.1002/btpr.2568, PMID 28960911.

60. Alavi M, Karimi N. Characterization, antibacterial, total antioxidant, scavenging, reducing power and ion chelating activities of green synthesized silver, copper and titanium dioxide nanoparticles using Artemisia haussknechtii leaf extract. Artif Cells Nanomed Biotechnol. 2018;46(8):2066-81. doi: 10.1080/21691401.2017.1408121, PMID 29233039.

61. Radhakrishnan R, Khan FL, Muthu A, Manokaran A, Savarenathan JS, Kasinathan K. Green synthesis of copper oxide nanoparticles mediated by aqueous leaf extracts of Leucas aspera and Morinda tinctoria. Lett Appl Nanobiosci. 2021;10(4):2706-14. doi: 10.33263/LIANBS104.27062714.

62. Singh A, Singh NB, Hussain I, Singh H. Effect of biologically synthesized copper oxide nanoparticles on metabolism and antioxidant activity to the crop plants Solanum lycopersicum and Brassica oleracea var. botrytis. J Biotechnol. 2017;262:1127. doi: 10.1016/j.jbiotec.2017.09.016, PMID 28962841. jbiotec.2017.09.016.

63. Asghar MA, Asghar MA. Green synthesized and characterized copper nanoparticles using various new plants extracts aggravate microbial cell membrane damage after interaction with lipopolysaccharide. Int J Biol Macromol. 2020;160:116876. doi: 10.1016/j.ijbiomac.2020.05.198, PMID 32464203.

64. Khatami M, Heli H, Mohammadzadeh Jahani P, Azizi H, Lima Nobre MA. Copper/copper oxide nanoparticles synthesis using Stachys lavandulifolia and its antibacterial activity. IET Nanobiotechnology. 2017;11(6):709-13. doi: 10.1049/ietnbt.2016.0189.

65. Desalegn Zeleke T. Copper nanoparticles synthesized using Echinops sp. root extract for antimicrobial applications. Int J Nano Dimens. 2021;12(2):145-55. doi: 20.1001.1.20088868.2021.12.2.7.4.

66. Punniyakotti P, Panneerselvam P, Perumal D, Aruliah R, Angaiah S. Anti-bacterial and anti-biofilm properties of green synthesized copper nanoparticles from Cardiospermum halicacabum leaf extract. Bioprocess Biosyst Eng. 2020;43(9):1649-57. doi: 10.1007/s00449-020-02357-x, PMID 32367495.

67. Thakur S, Sharma S, Thakur S, Rai R. Green synthesis of copper nano-particles using Asparagus adscendens roxb. Root and leaf 
extract and their antimicrobial activities. Int J Curr Microbiol App Sci. 2018;7(4):683-94. doi: 10.20546/ ijcmas.2018.704.077.

68. Kirubandanan S, Subha V, Renganathan S. Green synthesis of copper nanoparticles using methanol extract of Passiflora foetida and its drug delivery applications. Int J Green Chem. 2017;3(2):31-52.

69. Merugu R, Nayak B, Chitturi KL, Kumari Misra P. Bimetallic silver and copper nanoparticles synthesis, characterization and biological evaluation using aqueous leaf extracts of Majorana hortensis. Mater Today Proc. 2021;44:2454-8. doi: 10.1016/j.matpr.2020.12.516.

70. Santhosh Kumar J, Shanmugam V. Green synthesis of copper oxide nanoparticles from Magnolia champaca floral extract and its antioxidant and toxicity assay using Danio rerio. Int J Recent Technol Eng. 2020;8:5444-9. doi: 10.35940/ ijrte.E6869.018520.

71. Rafique M, Tahir MB, Irshad M, Nabi G, Gillani SSA, Iqbal T, Mubeen M. Novel Citrus aurantifolia leaves based biosynthesis of copper oxide nanoparticles for environmental and wastewater purification as an efficient photocatalyst and antibacterial agent. Optik. 2020;219. doi: 10.1016/j.ijleo.2020.165138, PMID 165138.

72. Shiravand S, Mahmoudvand H, Ebrahimi K. Biosynthesis of copper nanoparticles using aqueous extract of capparis spinosa fruit and investigation of its antibacterial activity. MPJ. 2017;21(4):866-71. doi: 10.12991/mpj.2017.31.

73. Balakrishnan G, Shil S, Vijalakashmi N, Rao MR, Prabhu K. Green synthesis of copper nanocrystallites using triphala churna and their anti-microbial studies. Drug Invent Today. 2019;12(9):2038-44.

74. Pariona N, Mtz-Enriquez AI, Sanchez Rangel D, Carrion G, Paraguay Delgado F, Rosas Saito G. Green-synthesized copper nanoparticles as a potential antifungal against plant pathogens. RSC Adv. 2019;9(33):18835-43. doi: 10.1039/C9RA03110C.

75. Padmavathi AR, P SM, Das A, Priya A, Sushmitha TJ, Pandian SK, Toleti SR. Impediment to growth and yeast-to-hyphae transition in Candida albicans by copper oxide nanoparticles. Biofouling. 2020;36(1):56-72. doi: 10.1080/ 08927014.2020.1715371, PMID 31997658.

76. Ponmurugan P, Manjukarunambika K, Elango V, Gnanamangai BM. Antifungal activity of biosynthesised copper nanoparticles evaluated against red root-rot disease in tea plants. J Exp Nanosci. 2016;11(13):1019-31. $10.1080 / 17458080.2016 .1184766$

77. Hao Y, Cao X, Ma C, Zhang Z, Zhao N, Ali A, Hou T, Xiang Z, Zhuang J, Wu S, Xing B, Zhang Z, Rui Y. Potential applications and antifungal activities of engineered nanomaterials against gray mold disease agent Botrytis cinerea on rose petals. Front Plant Sci. 2017;8:1332. doi: 10.3389/fpls.2017.01332, PMID 28824670.

78. Abboud MA. A novel biological approach to copper nanoparticles synthesis: characterization and its application against phytopathogenic fungi. Res Square. 2020. doi: 10.21203/rs.3. rs-125001/v1.

79. Viet PV, Nguyen HT, Cao TM, Hieu LV. Fusarium antifungal activities of copper nanoparticles synthesized by a chemical reduction method. J Nanomater. 2016;2016:1-7. doi: $10.1155 / 2016 / 1957612$.

80. Bramhanwade K, Shende S, Bonde S, Gade A, Rai M. Fungicidal activity of $\mathrm{Cu}$ nanoparticles against Fusarium causing crop diseases. Environ Chem Lett. 2016;14(2):229-35. doi: 10.1007/s10311-015-0543-1.

81. Shende S, Bhagat R, Raut R, Rai M, Gade A. Myco-fabrication of copper nanoparticles and its effect on crop pathogenic fungi. IEEE Trans Nanobioscience. 2021;20(2):146-53. doi: 10.1109/TNB.2021.3056100, PMID 33523815.

82. Pantano D, Neubauer N, Navratilova J, Scifo L, Civardi C, Stone V, von der Kammer F, Müller P, Sobrido MS, Angeletti B, Rose J, Wohlleben W. Transformations of nanoenabled copper formulations govern release, antifungal effectiveness, and sustainability throughout the wood protection lifecycle. Environ Sci Technol. 2018;52(3):1128-38. doi: 10.1021/acs.est.7b04130.est.7b04130. PMID 29373787.
83. Essa AM, Khallaf MK. Antimicrobial potential of consolidation polymers loaded with biological copper nanoparticles. BMC Microbiol. 2016;16(1):144. doi: 10.1186/s12866-016-0766-8, PMID 27400968.

84. Lalitha K, Kalaimurgan D, Nithya K, Venkatesan S, Shivakumar MS. Antibacterial, antifungal and mosquitocidal efficacy of copper nanoparticles synthesized from entomopathogenic nematode: Iinsect-host relationship of bacteria in secondary metabolites of Morganella morganii sp.(PMA1). Arabian J Sci Eng. 2020;45(6):4489-501. doi: 10.1007/s13369-020-04487-6.

85. Sriramulu M, Shanmugam S, Ponnusamy VK. Agaricus bisporus mediated biosynthesis of copper nanoparticles and its biological effects: an in vitro study. Colloids Interface Sci Commun. 2020;35:100254. doi: 10.1016/j.colcom.2020.100254. colcom.2020.100254, PMID 100254.

86. Jayakrishnan P, Razack SA, Sivanesan K, Sellaperumal P, Ramakrishnan G, Subramanian S, Sahadevan R. A facile approach towards copper oxide nanoparticles synthesis using spirulina platensis and assessment of its biological activities. Braz J Biol Sci. 2018;5(10):433-42. doi: 10.21472/bjbs.051020.

87. John MS, Nagoth JA, Zannotti M, Giovannetti R, Mancini A, Ramasamy KP, Miceli C, Pucciarelli S. Biogenic synthesis of copper nanoparticles using bacterial strains lisolated from an antarctic consortium associated to a psychrophilic marine ciliate: characterization and potential application as antimicrobial agents. Mar Drugs. 2021;19(5):263. doi: 10.3390/md19050263, PMID 34066868.

88. Rafique M, Shaikh AJ, Rasheed R, Tahir MB, Bakhat HF, Rafique MS, Rabbani F. A review on synthesis, characterization and applications of copper nanoparticles using the green method. Nano. 2017;12(04):1750043. doi: 10.1142/ S1793292017500436, PMID 1750043.

89. Din MI, Arshad F, Hussain Z, Mukhtar M. Green adeptness in the synthesis and stabilization of copper nanoparticles: catalytic, antibacterial, cytotoxicity, and antioxidant activities. Nanoscale Res Lett. 2017;12(1):1-5:638. doi: 10.1186/s11671-017-23998, PMID 29282555.

90. Slavin YN, Asnis J, Hafeli UO, Bach H. Metal nanoparticles: understanding the mechanisms behind antibacterial activity. J Nanobiotechnology. 2017;15(1):1-20:65. doi: 10.1186/s12951017-0308-z, PMID 28974225.

91. Dorobantu LS, Fallone C, Noble AJ, Veinot J, Ma G, Goss GG, Burrell RE. Toxicity of silver nanoparticles against bacteria, yeast, and algae. J Nanopart Res. 2015;17(4):1-3. doi: 10.1007/s11051-015-2984-7.

92. Gomaa EZ, Housseiny MM, Omran AAA. Fungicidal efficiency of silver and copper nanoparticles produced by Pseudomonas fluorescens ATCC 17397 against four Aspergillus species: a molecular study. J Cluster Sci. 2019;30(1):181-96. doi: 10.1007/s10876-018-1474-3.

93. Mahlo SM, Chauke HR, McGaw L, Eloff J. Antioxidant and antifungal activity of selected medicinal plant extracts against phytopathogenic fungi. Afr J Tradit Complement Altern Med. 2016;13(4):216-22. doi: 10.21010/ajtcam.v13i4.28. v13i4.28. PMID 28852739.

94. Salhi N, Mohammed Saghir SA, Terzi V, Brahmi I, Ghedairi N, Bissati S. Antifungal activity of aqueous extracts of some dominant Algerian medicinal plants. BioMed Research

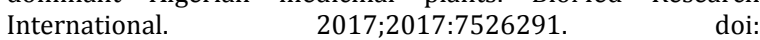
10.1155/2017/7526291, PMID 29226147.

95. Wang S, Zheng Y, Xiang F, Li S, Yang G. Antifungal activity of Momordica charantia seed extracts toward the pathogenic fungus Fusarium solani L. J. Food Drug Anal. 2016;24(4):881-7. doi: 10.1016/j.jfda.2016.03.006.jfda.2016.03.006. PMID 28911628.

96. Shahidi F, Zhong Y. Measurement of antioxidant activity. J Funct Foods. 2015;18:757-81. 10.1016/j.jff.2015.01.047.jff.2015.01.047.

97. Zou Z, Xi W, Hu Y, Nie C, Zhou Z. Antioxidant activity of citrus fruits. Food Chem. 2016;196:885-96. doi: 10.1016/j.foodchem.2015.09.072, PMID 26593569.

98. Karpinski TM, Adamczak A. Anticancer activity of bacterial proteins and peptides. Pharmaceutics. 2018;10(2):54. doi: 10.3390/pharmaceutics10020054, PMID 29710857. 
99. Lichota A, Gwozdzinski K. Anticancer activity of natural compounds from plant and marine environment. Int $\mathrm{J}$ Mol Sci. 2018;19(11):3533. doi: 10.3390/ijms19113533, PMID 30423952.

100. Sanjini NS, Winston B, Velmathi S. Effect of precursors on the synthesis of $\mathrm{CuO}$ nanoparticles under microwave for photocatalytic activity towards methylene blue and rhodamine b dyes. J Nanosci Nanotechnol. 2017;17(1):495-501. doi: 10.1166/jnn.2017.11785, PMID 29625519.

101. Joseph D, Baskaran S, Nagarajan M, Sivasubramnian S. Synthesis and characterization of silver nanoparticle from couroupita guianensis leaf extract and its effect on clinical pathogens. Asian J Pharm Clin Res 2020;12:117-21. doi: 10.22159/ajpcr.2020.v13i10.38859.

102. Das P. Nanoparticle insulin drug delivery-applications and new aspects. Int J Curr Pharm Sci. 2021;13(2):1-5. doi: 10.22159/ijcpr.2021v13i2.415482.

103. Kumar A, Pandit V, Nagaich U. Preparation and evaluation of copper nanoparticles loaded hydrogel for burns. Int J App Pharm. 2021;13(2):180-9

doi:

$10.22159 /$ ijap.2021v13i2.40558. 